Federal Reserve Bank of Minneapolis

Research Department Staff Report 506

January 2015

\title{
Migration, Congestion Externalities, and the Evaluation of Spatial Investments*
}

Taryn Dinkelman

Dartmouth College, NBER, BREAD, and Centre for Economic Policy Research

Sam Schulhofer-Wohl

Federal Reserve Bank of Minneapolis and BREAD

\begin{abstract}
The direct benefits of infrastructure in developing countries can be large, but if new infrastructure induces in-migration, congestion of other local publicly provided goods may offset the direct benefits. Using the example of rural household electrification in South Africa, we demonstrate the importance of accounting for migration when evaluating welfare gains of spatial programs. We also provide a practical approach to computing welfare gains that does not rely on land prices. We develop a location choice model that incorporates missing land markets and allows for congestion in local land. Using this model, we construct welfare bounds as a function of the income and population effects of the new electricity infrastructure. A novel prediction from the model is that migration elasticities and congestion effects are especially large when land markets are missing. We empirically estimate these welfare bounds for rural electrification in South Africa and show that congestion externalities from program-induced migration reduced local welfare gains by about $40 \%$.
\end{abstract}

Keywords: rural infrastructure, migration, congestion, welfare, program evaluation, South Africa JEL classification: O18, O15, R13, H43, H54, H23

\footnotetext{
*Dinkelman: Taryn.L.Dinkelman@Dartmouth.edu; Schulhofer-Wohl: wohls@minneapolisfed.org. We thank Tayyar Buyukbasaran and Yoon Sun Hur for excellent research assistance, Joan Gieseke for editorial assistance, and Eric Edmonds, Elaine Liu, Erzo F.P. Luttmer, Sandip Sukhtankar, and the editor and referees of the Journal of Development Economics for helpful comments. This research was funded by a grant from the International Growth Centre (RA-2009-11-016). The views expressed herein are those of the authors and not necessarily those of the Federal Reserve Bank of Minneapolis or the Federal Reserve System.
} 


\section{Introduction}

Governments in poor countries spend large sums on programs with spatial components, such as transport, sanitation, and energy infrastructure; schools, hospitals, and clinics; and irrigation facilities 1 A key feature of most such investments is that they take place in only part of a country, changing the relative attractiveness of certain regions for inhabitants. Standard approaches to evaluating the impacts of such development programs do not always account for the possibility that this change in relative attractiveness can induce a migration response. Much of the recent development literature measures the impact of new infrastructure on incumbent residents' outcomes along dimensions that the infrastructure directly affects, such as the effect of subsidized private tap connections on water use, health, well-being, and time use (Devoto et al., 2011, studying urban Morocco) or the impact of household electrification on home production technologies, employment, and earnings (Dinkelman, 2011, studying rural South Africa) ${ }^{2}$ While this direct approach provides some insight into the effects of spatial programs, by design it is not informative about how increased in-migration and reduced out-migration could alter the gains from a program of infrastructure investment. The omission of migration becomes particularly important when

\footnotetext{
${ }^{1}$ In Africa, spatial projects account for between $6 \%$ and $12 \%$ of GDP (Briceño-Garmendia, Smits, and Foster, 2008). The United States is a key contributor to infrastructure investments in developing countries, spending up to U.S. $\$ 50$ billion on such projects in 2009 (Lin and Doemeland, 2012).

${ }^{2}$ This direct approach has many other recent examples: Kremer et al. (2011) measure the impact of subsidized spring protection on disease incidence in rural Kenya; Cattaneo et al. (2009) estimate the impact of cement floors on child health, child cognition, and adult happiness in urban Mexico; Duflo and Pande (2007) measure the impact of irrigation dams on agricultural output and rural poverty in India; Donaldson (forthcoming) estimates the impact of Indian railroad expansion on agricultural prices and income levels and variability; Banerjee, Duflo, and Qian (2012) estimate the effect of transportation infrastructure on regional output in China; Lipscomb, Mobarak, and Barham (2013) estimate the impacts of hydropower electrification in Brazil on a host of economic outcomes.
} 
other local, rival, publicly provided goods, such as schools or hospitals, are in short supply: Any migration response to a location-based investment may end up congesting access to other such goods, thereby undermining welfare gains from the investment.

This paper is motivated by the idea that evaluations of place-based programs should account for migration responses and the related congestion externalities. We use a specific example - rural electrification in South Africa — to illustrate why and how migration could matter for evaluating welfare gains of spatial programs and propose a way to quantify these gains. Our example builds on the evaluation of the labor market effects of the rural electrification program in Dinkelman (2011). We begin by showing that the migration response to the program was very large, and we provide new evidence that the migration response was associated with congestion in households and in local schools.

In theory, one could account for the welfare consequences of migration responses to rural electrification and related congestion by estimating impacts of this investment on land prices and wages. Such an analysis would follow the urban and local public finance literatures (e.g., Albouy, 2009; Glaeser, 2007, 2008, Roback, 1982) that use land prices and wages to value place-based policies. Many authors have applied such methods in developed-country contexts, where land markets operate well and researchers can measure how the value of spatial investments is capitalized in housing prices and wages $3^{3}$ In practice, however, rural

\footnotetext{
${ }^{3}$ For example, Black (1999) measures the value of school quality by estimating how differences in otherwise-identical school neighborhoods are capitalized in housing prices, Davis (2011) examines how construction of a power plant reduces land values in a county, and Busso, Gregory, and Kline (2013) use land rents as a component of their estimated effects of federal Enterprise Zone policies. Fewer examples exist for developing countries, and where they do, they almost always occur in urban areas - for example, Lall and Lundberg (2008).
} 
South Africa is characterized by a lack of land markets: Land is communal and typically allocated through non-price mechanisms, which we describe in Section 2.A. The usual framework for using land prices to evaluate place-based policies is thus infeasible. This problem arises quite frequently in developing-country settings because missing markets for land are common (Adams, Cousins, and Manona, 1999; Udry, 2012) — land sales are prohibited in Ethiopia, and formal land title is lacking in large parts of the world, including rural India and Mexico (Banerjee and Duflo, 2007) — and even where land markets do exist, high-quality data on land rents often do not (Lozano-Gracia et al., 2013).

This paper provides an example of how one can address migration responses, related congestion externalities, and missing land markets in estimating the welfare effects of a spatial program. We adapt the spatial equilibrium model from Moretti (2011) to the case of rural electrification in South Africa. Individuals in our model choose between an urban area and a rural one; infrastructure improvements in the rural area cause people to migrate there 4 We model congestion by assuming an equal-sharing rule for the allocation of a rival publicly provided good. (Less extreme forms of congestion would produce similar but attenuated quantitative results.)

We use the stylized model to construct welfare bounds for the South African rural electrification program. The bounds arise because we do not know the distribution of tastes for living in the location that receives the program; the upper bound is reached when in-

\footnotetext{
${ }^{4}$ We model congestion in rural areas because our application focuses on rural infrastructure. But rural congestion is relevant more generally: Young (2013) provides new estimates from 65 poor and middle-income countries that while $20 \%$ of rural-born adults migrate to urban areas, $25 \%$ of urban-born adults migrate to rural areas. Moreover, rural areas are more likely to suffer from a lack of land markets than urban areas.
} 
migrants have as strong a preference as incumbents for living in the program location, and the lower bound is reached when in-migrants are almost indifferent between living in the program location and living elsewhere. Given credible estimates of the income and population effects of rural electrification and of relative preferences for public versus private goods, we can calculate these welfare bounds even when land markets or land price data are missing. We find that taking migration into account reduces the welfare benefit of rural household electrification by about $40 \%$.

Our paper makes three main contributions. First, we highlight why migration can be of first-order importance in understanding welfare impacts of spatial programs in developing countries. Our paper provides the first empirical evidence from a developing-country context that congestion effects exist and can be quantitatively large. While congestion externalities are important in urban economics, they have not yet received much attention in the development literature Quigley, 2008) ${ }^{5}$ Because there is no guarantee that governments in developing countries will be able to increase the supply of congestible local public goods even over very long periods of time, this is not merely a problem of the short run.

Second, our model highlights an often-overlooked but important theoretical concern: Migration responses to spatial programs are inefficiently large when land markets are missing. Without the information captured in land prices that could alert people to congestion externalities, less of a brake on migration is applied in response to a place-based program.

\footnotetext{
5 Usher (1977) examines the theoretical effects of international migration on access to public property. Rosenzweig and Wolpin (1986), in a study of family planning policies, show that program evaluation is difficult when there is selective migration in response to the policies and heterogeneity in the policies' treatment effects but do not explore the impact of migration on access to other publicly available services.
} 
We show that with no land market, the welfare benefits of a spatial program for both incumbents and movers are lower than they would be if a land market existed - a version of the tragedy of the commons. This excess migration is more likely to occur in developing countries where property rights are commonly unspecified and where access to publicly provided services such as education and health care is typically not priced.

Third, we illustrate how researchers might account for the welfare-reducing effects of congestion in a developing country, complementing traditional approaches to valuing the impact of place-based programs that rely on measures of land rents. By computing welfare bounds for the impact of rural household electrification in South Africa as a function of income and population responses to the program, we show it is feasible to account for migration when land markets are missing. While our model is designed to capture important characteristics of the particular economic context and infrastructure investment in our empirical application, the approach of calculating welfare effects without relying on housing price data is likely to have broad relevance because developing countries typically lack functional land markets or high-quality land price data.

One implication of our analysis is that researchers can learn much more about the effects of spatial programs in poor countries by using information about migration, rather than treating migration responses as a nuisance. Researchers conducting randomized controlled trials involving spatial treatments may be particularly well placed to measure migration externalities, if they collect appropriate data on population densities.

A few recent papers have begun to innovate in the use of randomized controlled trials 
to measure different types of spillover effects of programs with spatial components — for example, Crépon et al., 2013, studying job training programs in France, and Mobarak and Rosenzweig, 2014, studying insurance products in India. One approach has been to quantify negative spillover effects on program-related outcomes for nontreated individuals. A second approach is to use a structural model to trace out the impact of spatially targeted programs on welfare through price changes in general equilibrium. Our paper is related to this second approach. However, we highlight that when land price data do not exist, and in particular when land markets do not exist, we require a fundamentally different approach to estimate the welfare impact of a spatial investment program.

Our work carries some important caveats. First, we ignore urban agglomeration externalities and urban congestion effects, partly for tractability and partly because the evidence for (in particular) agglomeration externalities is scant in developed countries and nonexistent for developing countries Quigley, 2008). Without measuring urban welfare, our estimates of the welfare impacts of the rural electrification program are limited to rural areas. In Section 3.H, we discuss extensions to our model that allow for urban agglomeration and congestion effects. This discussion illustrates that the net impact of rural electrification on urban areas is not unambiguously positive, but rather depends on the relative size of congestion and agglomeration effects in cities. Determining the existence of positive agglomeration or negative congestion effects in urban areas is beyond the scope of this paper. In our quantitative analysis, we discuss how large (or small) the impact on urban areas would need to be to eliminate remaining positive impacts of rural electrification or to make a substantial difference to the 
upper bound on our welfare estimates.

A second, related caveat is that we use a partial-equilibrium model. We assume that overall migration effects are small enough so that the effects of out-migration in other parts of the country are ignorable, but we also discuss how the model could be modified to account for this general equilibrium concern. Third, we ignore the questions of how to optimally finance local programs through taxation ${ }^{6}$ and how to optimally allocate spatial investments; to highlight how congestion affects welfare, we focus on estimating welfare gains from local programs in the places where these local programs occur. Finally, our analysis is static; we do not consider the dynamic effects of place-based policies.

The paper begins by describing the example of a spatial investment that motivates our paper: rural household electrification in South Africa. We briefly review the context and methods in Dinkelman (2011) and describe the particular institutions of land allocation in these rural areas that lead us to develop a model with missing land markets. We provide new estimates of the population and congestion effects of this infrastructure investment. The next part of the paper develops a two-period model of location choice under the assumption of missing land markets. We derive equilibrium conditions for period 1 and describe the new equilibrium after a local infrastructure project is implemented in period 2. Crucially, the characteristics of this new equilibrium depend on whether we allow a land market in the second period. We derive formulae for the compensating variation of the program and welfare

\footnotetext{
${ }^{6}$ Typically, the local public finance literature takes into account both the benefit incidence of local programs as well as the cost incidence in terms of who pays the taxes that fund local programs. Tiebout (1956) is a classic reference; Wildasin (1991) and Calabrese, Epple, and Romano (2012) provide more recent analyses focusing on questions of incidence.
} 
bounds for the impact of the program as functions of income and migration (population) elasticities. We discuss several extensions to the model that allow infrastructure to be an amenity, allow production to be decreasing returns to scale, and address general equilibrium concerns by including urban agglomeration and congestion effects. Finally, we implement the bounds from our model given consistent estimates of the relevant model parameters from the South African case.

\section{Rural household electrification in South Africa}

Electric service is a classic example of an infrastructure good that is tied to place. Because electrification changes living conditions and work possibilities, the relative attractiveness of living in a community could change when it gets electricity. In South Africa, rural electrification directly affected labor market outcomes and induced migration. We begin by reviewing the program of rural electrification in South Africa and describing a key feature of the institutional setting in which this infrastructure development took place: a setting of missing land markets. We recap the empirical strategy used in Dinkelman (2011) and report the effects of the program on migration, measured by changes in population. Using the same empirical strategy and new data, we present additional evidence that program-induced migration resulted in congestion in households and in local schools. The details of this example inform the structure of the model that we use to compute welfare bounds. 


\section{A. Program description, institutional setting, and prior estimates of program impact}

Between 1995 and 2001, roughly 200,000 households in rural KwaZulu-Natal (KZN) benefited from new electricity connections installed by South Africa's national power utility, Eskom $7^{7}$ Connections were free, and although electricity was priced (at a low rate), most households could afford to light their homes and some were able to purchase power for cooking. Dinkelman (2011) identifies the causal impact of this infrastructure rollout on employment using an instrumental variables strategy relying on land gradient, a key factor affecting the cost of providing household connections.

Using community-level Census data from before and after the program matched to administrative data on the location and timing of electrification projects and to geographic features of the communities (land gradient, distance from roads and towns, and distance from electricity substations), Dinkelman (2011) finds that employment rises for women and men in electrifying communities. These direct effects on employment are driven by increases in female labor force participation: The IV results indicate a significant 9 percentage point increase in female employment in electrified communities.

A key feature of the communities in this study is the absence of a market-based system for land transactions, along with unpriced publicly provided goods and services. Land is largely state owned or held in trust, often untitled, and communally operated. As in many other parts of Africa (Adams, Cousins, and Manona, 1999), local chiefs, kin-based networks, or tribal authorities decide who can access land and for what purposes (residential, cropping,

\footnotetext{
${ }^{7}$ See Dinkelman 2011$)$ for a detailed discussion of the program.
} 
or communal grazing), although details of these allocation mechanisms are unclear. $8^{8}$ Without a land market, newcomers to a rural community may gain access to land and housing by moving in with relatives and increasing household size. They may also occupy communal land illegally, as squatters. In our empirical example, such land occupation was facilitated by the complete breakdown of the land administration regime in rural ex-homeland areas and the resulting increase in uncertainty over land rights in the post-apartheid period Adams, Cousins, and Manona, 1999; Lahiff, 2001). In addition to land, the provision of and access to many publicly provided goods, such as local schools, health clinics, and water infrastructure, is also outside the ambit of the market. The state provides these goods and services for all residents in a given locality, and access is often determined through queueing.

The absence of a land market in this rural setting means that we cannot use estimates of the wage and land price effects of the program to measure the value of the new electricity infrastructure to consumers. Despite this difficulty, we will show that it is still possible to say something about the welfare effects of the program by using the structure of a location choice model along with estimates of the population's income and population effects. In the process, our model will yield some novel insights into how the lack of land markets leads to excess congestion in other local publicly provided goods.

Before turning to the model, we provide empirical evidence on the population impacts of the South African electrification and associated congestion externalities.

\footnotetext{
${ }^{8}$ Historically, chiefs were supposed to discern good from bad community members and newcomers, and so protect the community from unsavory types (Hall, 2009). In practice, kin networks often receive preferential treatment in the allocation of land.
} 


\section{B. Population and congestion effects of rural electrification Empirical methods and data}

Dinkelman (2011) provides some estimates of the impact of electrification on total population. We extend these results to show the direct effects of providing this new infrastructure on the number of individuals older and younger than 14 years of age in electrifying communities, and on household density and household size. To do so, we follow the same instrumental variables empirical strategy:

$$
\begin{aligned}
& \Delta y_{j d t}=\nu_{1}+\nu_{2} \Delta I_{j d t}+\nu_{3} X_{j d 0}+\nu_{d}+\Delta \epsilon_{j d t} \\
& \Delta I_{j d t}=\delta_{1}+\delta_{2} Z_{j d}+\delta_{3} X_{j d 0}+\delta_{d}+\Delta \omega_{j d t}
\end{aligned}
$$

where $\Delta y_{j d t}$ is the change in the outcome variable (such as population) in community $j$ and district $d$ between 1996 and 2001, and where $\Delta I_{j d t}=1$ if a community was electrified between 1996 and 2001. $X_{j d 0}$ controls for baseline characteristics of the community including household density and distance from the initial grid, $\nu_{d}$ and $\delta_{d}$ are district-specific trends, and $\epsilon_{j d t}$ and $\omega_{j d t}$ are community-specific error terms. Since there are good reasons to suspect that electricity projects were not assigned randomly, and to be concerned about correlation between project assignment and unobservable community-level trends (i.e., to suspect that $\left.E\left[\Delta \epsilon_{j d t} \Delta I_{j d t}\right] \neq 0\right)$, Dinkelman (2011) instruments for $\Delta I_{j d t}$ with community land gradient $Z_{j d}$. The identification assumption is that, conditional on controls, population growth trends should not be different across communities with steeper versus flatter land gradients.

To provide evidence for local congestion effects in the wake of the migration response 
to the program, we supplement the community-level data set with spatially matched data from South Africa's national School Register of Needs Survey (also before and after electrification) and assign school-level variables to communities in which schools are located. We estimate the indirect effects of electrification through crowding using the same system of equations in (1), the change in student-teacher ratio and number of learners per school as outcomes, and check that the number of schools does not increase in electrifying communities over the same time period.

\section{Population and congestion results}

Table 1 presents key summary statistics. Between 1996 and 2001, about 20\% of the 1,816 rural communities received free Eskom electrification. The employment rate in the baseline period is $10 \%$, an extremely low level of participation. Because these former homeland areas have poor land, employment opportunities were very sparse (Dinkelman, 2011). At baseline, household density is relatively high - 22 households per square kilometer - and the average household size is under 4, with a wide range (2 to 14). Each community has on average 0.94 schools, also with a wide range: Some communities contain no schools, while other, larger communities have up to 11 schools. Conditional on having at least one school in the area, average student-teacher ratios (STRs) are high, at 39 for an average community. Some schools serve very small populations and have just four learners per teacher, while other schools are burdened with STRs of over 100.

Table 2, Panel A, presents evidence on the migration response to the program. The first two columns reproduce the OLS and IV population growth regressions from Dinkelman 
(2011).9 Population grows by $3.8 \log$ points over five years in electrifying communities. The $95 \%$ confidence interval is wide, and at the lower bound, electrification increases districtlevel population by a factor of about 4 . Even this lower bound is a massive effect ${ }^{10}$ On average across all communities, annual population growth is between $2 \%$ and $3 \%$, but there is substantial heterogeneity (the standard deviation is $12 \%$ ). Some very small communities grow enormously, while other, larger communities, grow at slower rates. The evidence in Table 2 suggests that electrifying communities grew particularly fast. This growth is far larger than the natural increase in population can explain. The growth rate of the adult population (ages 14 to 60 ) is even higher than the growth rate of the child population (under age 14) in electrifying communities. The final two columns of Panel A in the table show that the increased number of adults and children in electrifying communities resulted in a substantial increase in household density. Electrifying areas become fives times more dense than the average over five years (again, with a very wide confidence interval). These changes in population reflect the change in relative attractiveness of electrifying communities as a result of the infrastructure program $\sqrt{11}$

\footnotetext{
${ }^{9}$ Appendix A3 presents the first-stage regression results for the instrumental variables regressions in Table 2. The excluded instrument is land gradient, and the F-statistic on this instrument is 8.26 ( $p$-value $=0.00)$. This relatively weak instrument means that the effects of the program will be difficult to measure precisely, which will in turn mean that our welfare bounds will be estimated with less precision than we would like.

${ }^{10}$ We have checked that the large IV coefficients for population growth are not driven by outliers or by functional form. Because we use these IV estimates to calculate the welfare effects of electrification, our welfare bounds will be Local Average Treatment Effects capturing the welfare effect of the program for areas induced into treatment by the instrumental variable we use. However, this limitation of our results is a property of the particular instrumental variable rather than of our method for adjusting for migration impacts; if causal estimates of the program's average treatment effect were available, they could be used in constructing our welfare bounds.

${ }^{11}$ Unfortunately, the data on the number of in-migrants to these areas are not very well measured, making it difficult to precisely estimate the impact of electrification on the number of in-migrants to electrifying areas.
} 
The results in Table 2, Panel B, show how this growth in population in electrifying communities led to crowding in other local congestible public goods. In column 2 of Panel B, we see the IV estimates of the impact of electrification on household size. In places getting access to electricity between 1996 and 2001, household size increases by almost one person. This is a large increase relative to average household size (3.62) and the median number of rooms per house for this sample (3).

The next set of columns show the consequences for access to schooling. (Unfortunately, there are no data on patients served by local clinics or hospitals that could be used to show congestion in other important publicly provided congestible services.) Schools become more crowded in areas getting access to electricity by virtue of gradient: Student-teacher ratios increase by more than 26 students on average, or about $66 \%$ relative to the average STR. The number of school-registered learners in each community increases by a large (but not statistically significant) 239 students, or $27 \%$. Importantly, the final two columns of Panel B show no evidence that the number of schools in electrifying areas is increasing over the period. At least in the short run (five years), important local publicly provided goods (other than electricity) are not elastically supplied in these areas.

These results on congestion in communities, in households, and in public schools after rural electrification represent some of the first empirical estimates of congestion externalities in a developing country. They highlight a powerful channel through which migration may have negative consequences for at least some incumbents. ${ }^{12}$

\footnotetext{
${ }^{12}$ For example, if recent empirical evidence from the United States (Chetty et al. 2011 ) is any guide, then larger class sizes (higher STRs) may have negative effects on human capital attainment in the short run and on educational attainment, savings, and home ownership in the long run.
} 
To summarize: Rural electrification in South Africa provides us with a classic example of a spatial program that affected specific communities. This program increased employment for incumbents, induced population growth through in-migration and likely reduced outmigration, and led to congestion in households and schools. Since this migration response occurred in a setting without land prices, we require a model to measure the welfare effects of the electrification program. The rest of the paper sets up such a model, then combines it with the empirical estimates of income and population effects of rural electrification to estimate welfare bounds.

\section{Welfare effects of rural electrification in the presence of migra- tion: a model}

This section describes how one can use a simple model of migration to value a placebased development program such as rural electrification. We adapt the spatial equilibrium model of Moretti (2011) to the South African rural electrification case. We innovate by contrasting the model's solutions in two distinct institutional settings: one in which there is no land market and another in which such a market exists. We show that differences in migration responses and related congestion externalities drive a wedge between the two solutions, so that rural electrification produces smaller welfare benefits when there is no land market. We show how the model structure can be used to estimate welfare bounds for this infrastructure investment when land markets are missing or land prices are not measured.

Our baseline model is designed to match several important characteristics of the South African context. For example, we assume that production has constant returns to scale. In extensions, we show some ways in which the model could be enriched to apply to other 
contexts and demonstrate that the key qualitative findings are robust to these extensions. We primarily focus on measuring the impact of the spatial investment on rural areas but also show how our findings would change if we extended the model to consider impacts on urban areas that supply rural migrants.

\section{A. Preferences and endowments}

There are two time periods, $t=1,2$. In each period, a given consumer $i$ chooses whether to live in an urban area or a rural area. ${ }^{13}$ For simplicity, and to match what we are able to do in our empirical work, we assume that different individuals consider different rural areas as their alternative to the urban location but that each individual may consider only one rural area as a possible location. Consumers are myopic: In each period, they consider only that period's utility in deciding where to live, and they choose whichever location gives them the highest utility.

In each period, all consumers receive the same utility $\bar{U}$ from living in the urban area. Consumer $i$ 's utility of living in the rural area in period $t$ is

$$
U_{i}\left(c_{t}, a_{t}\right)=c_{t}^{\alpha} a_{t}^{1-\alpha}+\epsilon_{i}
$$

where $c_{t}$ is a freely tradable consumption good; $a_{t}$ is person $i$ 's share of some local publicly provided good; and $\epsilon_{i}$ captures heterogeneity in preferences for living in the rural area, uniformly distributed on the interval $[-s, s]$.

\footnotetext{
${ }^{13}$ We use the labels "urban" and "rural" for ease of exposition. However, the core idea is that individuals are choosing between only two places, one of which — the place labeled "urban" — is outside the reach of the program we are evaluating. We discuss extensions to this assumption below.
} 
The publicly provided good $a_{t}$ is a reduced form for any rival, potentially excludable, nontraded good, such as schooling, health-care services, congestion in communal land from in-migrants who occupy public spaces, as well as congestion in households from in-migrants who move into existing households with relatives (as the household size results in Table 2 suggested). We assume that $a_{t}$ enters directly into utility, rather than serving as a factor of production, because much of the land in rural South Africa is not suitable for farming and because many local publicly provided goods we have in mind, such as schooling, are at best investments that affect future productivity but not current productivity. For the rest of our analysis, we refer to $A$ as land and $a_{t}$ as an individual's share of that land (again bearing in mind that these variables could represent any rival, nontraded good that is fixed in supply at the local level, such as schools, clinics, water infrastructure, or space in existing housing).

The taste shock $\epsilon_{i}$ does not change over time for a given individual. Preference heterogeneity implies that some individuals will be inframarginal in the spatial equilibrium and will not be indifferent between rural and urban locations. These individuals capture utility rents in equilibrium; heterogeneity in preferences prevents migration from arbitraging away all of the gains from local infrastructure programs ${ }^{14}$ The assumption of a uniform distribution for preferences gives us tractable expressions for the program's quantitative effect but is not crucial for the qualitative results. The parameter $s$ measures how much variation there is in the strength of consumers' attachment to the rural area. If $s$ is large, some individuals are strongly attached to the rural area and will prefer the city only given

\footnotetext{
${ }^{14}$ See Moretti (2011) and Busso, Gregory, and Kline (2013) for discussions of the role of heterogeneity in spatial equilibrium models.
} 
large reductions in $c_{t}$ or $a_{t}$.

Each consumer has a time endowment $T_{t}$ that she supplies inelastically to the market.

We assume that rural consumers have exogenously given productivity $w_{t}$ per unit time, regardless of the rural population, and are paid their marginal product when they work. Under these assumptions, labor income is $w_{t} T_{t}$. Given our assumptions, employers earn zero profits regardless of the infrastructure investment, so we need to keep track only of consumers' welfare to measure the welfare impact of the investment.15

The rural area has a perfectly elastic supply of the consumption good, which we treat as numeraire, and a perfectly inelastic supply $A$ of land. In the first time period, there is no market for land; rather, it is rationed equally across all consumers who choose to live in the rural area. By adopting this "equal-sharing" rule, we simplify the non-market-based allocation of the local public good described in Section 2.A. This simplification allows us to examine what a complete lack of markets for these goods implies for migration responses to local programs. Imperfect markets for such publicly provided goods are likely to have similar, although attenuated, effects.

Under the equal-sharing rule for land, the budget set in the rural area in the first period is

$$
c_{1} \leq w_{1} T_{1}, \quad a_{1}=\frac{A}{N_{1}},
$$

where $N_{1}$ is the number of consumers in the rural area in period 1 . We will investigate

\footnotetext{
${ }^{15}$ Decreasing returns to scale do not change our qualitative results, but in contexts where decreasing returns are important, researchers would want to add this feature to the model to obtain accurate quantitative results. We show how to do this in Section 3.G.
} 
two alternative allocation mechanisms for land allocation in period 2: equal sharing and market-based allocation.

\section{B. Equilibrium in period 1: before the program}

An equilibrium in period 1 is a consumption choice for each consumer and an assignment of consumers to locations such that, given $\bar{U}$, each consumer's consumption and location choices maximize utility, taking the rationing of the publicly provided good as given. The indirect utility of living in the rural area in period 1 is

$$
\begin{aligned}
U_{i 1}^{*} & =\max _{c, a} c^{\alpha} a^{1-\alpha}+\epsilon_{i} \quad \text { s.t. } \quad c \leq w_{1} T_{1}, \quad a=\frac{A}{N_{1}} \\
& =\left(w_{1} T_{1}\right)^{\alpha}\left(\frac{A}{N_{1}}\right)^{1-\alpha}+\epsilon_{i} .
\end{aligned}
$$

Thus, $i$ chooses to live in the rural area in period 1 if and only if $U_{i 1}^{*} \geq \bar{U}$, or

$$
\epsilon_{i} \geq \bar{U}-\left(w_{1} T_{1}\right)^{\alpha}\left(\frac{A}{N_{1}}\right)^{1-\alpha} \equiv \bar{\epsilon}_{1}
$$

This result defines a cutoff for the preference shock $\overline{\epsilon_{1}}$, below which individuals choose to stay in the urban area and above which individuals choose the rural area.

\section{Modeling the effect of infrastructure}

We assume that the rural electrification program raises income, $w_{t} T_{t}$, in the rural area by changing the time endowment. For example, household electrification can allow women to devote more time to market work by reducing the time they must spend gathering firewood for cooking. Although electrification potentially makes workers more productive on the job 
(thereby possibly affecting $w_{t}$ ), this did not occur in South Africa (see Dinkelman, 2011).

We assume the infrastructure program does not affect urban utility $\bar{U}$. This amounts to assuming that migrants out of the urban area represent a small fraction of the urban population, even though they may be a large fraction of the rural population. This assumption also rules out potential benefits or costs to the urban area arising from people leaving the urban area. We discuss in Section 3.H how relaxing this assumption would change our equilibrium and the calculation of welfare benefits.

\section{Equilibrium in period 2}

We now characterize the spatial equilibrium that arises in period 2 , after the infrastructure program is implemented. The nature of the post-program equilibrium depends on the form of the market for land.

\section{No land markets}

Suppose that, in period 2, land is again rationed across consumers who choose to live in the rural area. Then the equilibrium is identical to that in period 1, except that $w_{2} T_{2}>w_{1} T_{1}$; consumer $i$ chooses to live in the rural area in period 2 if and only if

$$
\epsilon_{i} \geq \bar{U}-\left(w_{2} T_{2}\right)^{\alpha}\left(\frac{A}{N_{2}}\right)^{1-\alpha} \equiv \bar{\epsilon}_{2}
$$

The fraction of individuals living in the rural area is the same as the probability that $\epsilon_{i} \geq \bar{\epsilon}_{2}$. Hence, using the uniform distribution of $\epsilon_{i}$, we can write the local labor supply 
function,

$$
s \frac{2 N_{2}-P}{P}=\left(w_{2} T_{2}\right)^{\alpha}\left(\frac{A}{N_{2}}\right)^{1-\alpha}-\bar{U}=-\bar{\epsilon}_{2},
$$

where $P$ is the total population in the urban and rural areas. The left-hand side of $(7)$ is strictly increasing in $N_{2}$, while the right-hand side is strictly decreasing in $N_{2}$ and strictly increasing in $w_{2} T_{2}$. Therefore, the equilibrium population $N_{2}$ is strictly increasing in income $w_{2} T_{2}$; more people live in the rural area after the infrastructure is built (or, $\bar{\epsilon}_{2}<\bar{\epsilon}_{1}$ ).

Because the indirect utility of the rural area is monotonic in $\epsilon_{i}$, anyone who chose the rural area in period 1 will continue to choose it when rural income rises in period 2. Thus, after the infrastructure program, two kinds of people are in the rural area: rural stayers, who lived in the rural area in period 1 and remain there in period 2, and movers, who lived in the urban area in period 1 but are induced by higher incomes to move to the rural area in period 2. We will take into account the welfare gains of the program accruing to both rural stayers and movers in constructing our welfare bounds.

\section{With a land market}

Suppose alternatively that in period 2, there is a market for land: It can be bought and sold at price $\hat{r}_{2}$. (Land might be traded for a price, or, if we consider schooling or health services as the local, rival publicly provided good, slots in school could be "bought" for a school fee, or private health care might be available.) To keep notation clear, we will use hats to denote all variables corresponding to the equilibrium with a market for the local public good. We assume that the people who lived in the rural area in period 1 (when land was rationed) own equal shares of the land endowment. We continue to assume the infrastructure 
program raises incomes (i.e., $w_{2} T_{2}>w_{1} T_{1}$ ). We show below that, as in the no-markets case, this assumption implies that no one who lives in the rural area in period 1 moves away in period 2. Thus, we must continue to distinguish between rural stayers and movers into the rural area. The period 2 budget constraints of rural stayers and movers are

$$
\begin{aligned}
& \hat{c}_{2, \text { stayer }}+\hat{r}_{2} \hat{a}_{2, \text { stayer }}=w_{2} T_{2}+\hat{r}_{2} \frac{A}{N_{1}} \\
& \hat{c}_{2, \text { mover }}+\hat{r}_{2} \hat{a}_{2, \text { mover }}=w_{2} T_{2} .
\end{aligned}
$$

An equilibrium in period 2 with a land market is a price $\hat{r}_{2}$, consumption and land choices for each consumer, and an assignment of consumers to locations such that, given $\bar{U}$, (i) each consumer's consumption and location choices maximize utility, taking the land price as given, and (ii) the land market clears. We show in Appendix A1 that, in the equilibrium, the indirect utilities of rural stayers and movers are

$$
\begin{aligned}
& \hat{U}_{i 2, \text { stayer }}^{*}=\alpha\left(1+\frac{1-\alpha}{\alpha} \frac{\hat{N}_{2}}{N_{1}}\right)\left(w_{2} T_{2}\right)^{\alpha}\left(\frac{A}{\hat{N}_{2}}\right)^{1-\alpha}+\epsilon_{i} \\
& \hat{U}_{i 2, \text { mover }}^{*}=\alpha\left(w_{2} T_{2}\right)^{\alpha}\left(\frac{A}{\hat{N}_{2}}\right)^{1-\alpha}+\epsilon_{i} .
\end{aligned}
$$

Because stayers collect rents, they have higher indirect utility than movers for any given value of $\epsilon_{i}$. Therefore, if anyone who started in the rural area moves out, no one will move in - all of the potential in-migrants have lower $\epsilon_{i}$ and would have to pay rent, besides.

The effect of creating a market for land on migration depends on whether $w_{2} T_{2}$ is 
larger than $w_{1} T_{1}$. If $w_{2} T_{2}=w_{1} T_{1}$, creating a market does not change incumbents' budget sets. Hence, if $w_{2} T_{2}=w_{1} T_{1}$, then $N_{2}=N_{1}$ regardless of whether there is a land market in the second period ${ }^{16}$ This result says that, without the infrastructure program, having a market does not change the equilibrium allocation and thus does not change welfare. Thus, we can analyze how markets change the welfare impact of the program by comparing post-program welfare in the market and no-market cases.

If $w_{2} T_{2}>w_{1} T_{1}$, the number of people who move to the rural area depends on whether there is a land market. First, if $w_{2} T_{2}>w_{1} T_{1}$, it cannot be an equilibrium for anyone to move out: Just as in the no-markets case, because rural incomes in period 2 are larger than they were in period 1 , no one who preferred the rural area in period 1 will prefer the urban area in period 2. Second, a person who was in the urban area in period 1 will move to the rural area in period 2 if and only if $\hat{U}_{i 2, \text { mover }}^{*} \geq \bar{U}$, or

$$
\epsilon_{i} \geq \bar{U}-\alpha\left(w_{2} T_{2}\right)^{\alpha}\left(\frac{A}{\hat{N}_{2}}\right)^{1-\alpha} \equiv \hat{\bar{\epsilon}}_{2} .
$$

Depending on the parameters of the model, $\hat{\bar{\epsilon}}_{2}$ may be larger or smaller than $\bar{\epsilon}_{1}$. If $\hat{\bar{\epsilon}}_{2} \geq \bar{\epsilon}_{1}$, no one moves to the rural area; the populations remain the same. This would be the case if the increase in income driven by the new infrastructure was exactly offset by an increase

\footnotetext{
${ }^{16}$ The proof of this claim is by contradiction. If creating a land market caused the rural population to fall, then for people who were in the rural area in period 1, the period 1 consumption bundle would remain feasible in period 2 for any value of $\hat{r}_{2}$ and would be preferred to living in the urban area, implying that all of the initial rural residents would prefer to stay and contradicting the hypothesis that the rural population falls. Alternatively, if creating a land market caused the rural population to rise, anyone who preferred the urban area in period 1 must still prefer it in period 2, when wages are no higher than before and in-migrants must pay rent, contradicting the hypothesis that the rural population rises.
} 
in rents to be paid by any movers. If $\hat{\bar{\epsilon}}_{2}<\bar{\epsilon}_{1}$, some people move to the rural area and its population increases. Regardless of the parameters, we have the following result:

Proposition 1. The migration response to an increase in the time endowment caused by the local infrastructure program is strictly smaller when there is a market for land (i.e., $\left.\hat{N}_{2}<N_{2}\right)$.

Proof. The migration response without a land market is strictly positive. If $\hat{\bar{\epsilon}}_{2} \geq \bar{\epsilon}_{1}$, then the migration response with a land market is zero, which is strictly less than the response without a land market. If $\hat{\epsilon}_{2}<\bar{\epsilon}_{1}$, the rural population in period 2 with a land market satisfies

$$
s \frac{2 \hat{N}_{2}-P}{P}=\alpha\left(w_{2} T_{2}\right)^{\alpha}\left(\frac{A}{\hat{N}_{2}}\right)^{1-\alpha}-\bar{U} .
$$

The left-hand sides of (7) and (11) are identical and are both strictly increasing in the rural population. Since $\alpha \in(0,1)$, the right-hand side of $(11)$ is strictly less than the right-hand side of (7) for a fixed value of the rural population. Further, the right-hand sides of both equations are strictly decreasing in the rural population. Thus, the rural population that solves (7) - the no-markets equilibrium population — is strictly greater than the equilibrium population with a market, which solves (11).

Proposition 1 is the first main theoretical result from our model. The proposition demonstrates that more people move into the rural area in response to a local infrastructure program when the land market is missing. Put differently, when a market for land exists, the price of land gives consumers information about crowding and acts as a brake on migration. 
In essence, this is a version of the tragedy of the commons. When individuals move into a rural area after the program, congestion in the local publicly provided good $A$ is taken account of only when that good is priced. In contrast, when anyone in the rural area can access the congestible good, the migration response to the program is higher, which reduces welfare 17

Although the migration response is strictly smaller when there is a land market, the existence of a land market does not ensure a socially optimal distribution of people across rural and urban locations. This is because, in the model, the only way for landlords to collect rent from rural property is for them to remain in rural areas. Hence, if the rural area is initially overcrowded compared with the efficient allocation, creating a land market will not induce people to leave the rural area. The implication is that while land markets enable rents to act as a brake on migration, the creation of land markets does not by itself guarantee efficiency.

\section{E. Bounding the welfare effects of the infrastructure investment}

The main contribution of this paper is to show how one can estimate welfare effects of a place-based development program in a manner that accounts for migration responses but does not require data on land prices. With our stylized model in hand, we are ready to

\footnotetext{
${ }^{17}$ Unpriced amenities in our model also stand in for any unpriced local nontradeables. If local nontradeables (e.g. services, such as hairdressing) are instead priced, congestion in the wake of in-migration will also be reflected in real income. People will account for these price changes by considering real (rather than nominal) income gains from moving. Taking account of this congestion in the quantitative exercise would therefore require measuring real income. Unfortunately, in our empirical exercise, we do not have local price indices and so are limited to measuring changes in nominal income after an electricity project. This limitation implies that we potentially overestimate (real) income gains from electrification as well as welfare gains from the program.
} 
compute the welfare impact of rural household electrification using consumers' compensating variation: the reduction in income, after the program, that would leave the consumer just indifferent between not having the program or having the program but paying for it with a reduction in income ${ }^{18}$ (Recall that firms earn zero profits in our model, so the program affects welfare only by affecting consumers' welfare. Also, we ignore urban welfare for now and return to a discussion of this in Section 3.H.) Specifically, for each person in the rural area in period 2 - both stayers and movers — we ask: For what number $k$ would a $100 k \%$ reduction in the rural wage, after the program, return this person to his or her period 1 utility level? The answer depends both on the crowding induced by the project and on the structure of the market for land.

\section{No land market}

For rural stayers, we must find the $k$ that solves

$$
\left[\left(1-k^{\text {stayer }}\right) w_{2} T_{2}\right]^{\alpha}\left(\frac{A}{N_{2}}\right)^{1-\alpha}=\left(w_{1} T_{1}\right)^{\alpha}\left(\frac{A}{N_{1}}\right)^{1-\alpha}
$$

Rearranging terms,

$$
-\ln \left(1-k^{\text {stayer }}\right)=\ln \frac{w_{2} T_{2}}{w_{1} T_{1}}-\frac{1-\alpha}{\alpha} \ln \frac{N_{2}}{N_{1}}
$$

Equation (13) provides a useful decomposition of the program's welfare impact. The

\footnotetext{
${ }^{18}$ The use of compensating variation is not uncommon in the local public finance literature - for example, Calabrese, Epple, and Romano (2012). To calculate the equivalent variation, we would need an explicit model of consumers' maximization problem in the urban area. The compensating variation allows us to sidestep this issue, but it does have costs. Primarily, it is impossible to compare benefits of different types of programs using compensating variation, since the new prices used to value the welfare change are different for each kind of intervention.
} 
first term on the right-hand side is the program's income effect; the second is the congestion effect caused by migration. The argument of our paper is that this congestion effect can be just as important as the income effect when the migration response to the program, $\ln \left(N_{2} / N_{1}\right)$, is not small and when the preference for the local, rival publicly provided good does not substantially outweigh the preference for the consumption good $((1-\alpha) / \alpha$ is not too small) 19

Since any mover has $\bar{\epsilon}_{2} \leq \epsilon_{i}<\bar{\epsilon}_{1}$,

$$
0 \leq-\ln \left(1-k_{i}^{\text {mover }}\right)<-\ln \left(1-k^{\text {stayer }}\right) .
$$

Also, because all agents in our model have the same income, we can aggregate the compensating variation across individuals:

$$
C V=\sum_{\text {stayers }} k^{\text {stayer }} w_{2} T_{2}+\sum_{\text {movers }} k_{i}^{\text {mover }} w_{2} T_{2}
$$

The bounds in (14) then imply the following bounds on welfare:

$$
N_{1} k^{\text {stayer }} w_{2} T_{2} \leq C V<N_{2} k^{\text {stayer }} w_{2} T_{2} .
$$

At the lower bound, the compensating variation to the marginal mover is zero; at

\footnotetext{
${ }^{19}$ Different assumptions about the functional form of congestion in a particular publicly provided good or the presence of agglomeration effects could affect the specific form of equation (13). However, as long as in-migrants create some congestion (or contribute agglomeration externalities), the migration response to the initial spatial program will appear as part of the compensating variation.
} 
the upper bound, the marginal mover gains just less than the utility gain that rural stayers enjoy. Empirically calculating these bounds does not require any information about who is

a mover or stayer. Rather, all we need are estimates of $k_{\text {stayer }}$, which is itself a function of the program's effect on income $\left(w_{2} T_{2} / w_{1} T_{1}\right)$ and population $\left(N_{2} / N_{1}\right)$ and of $\alpha$, the relative preference for consumption goods. In Section 4, we show that equation (13) is straightforward to estimate from data on the infrastructure program's impact on income and population, and we describe ways to choose sensible values of $\alpha$.

Although our model does not explicitly include moving costs, adding heterogeneous moving costs would not change the calculation of the welfare bounds - only their interpretation. At one extreme, movers gaining zero utility from moving can be thought of as paying a moving cost equal to their entire utility gain from rural consumption and rural land; at the other extreme, movers with no moving cost enjoy the same gain in utility as the stayers do.

\section{With a land market}

For rural stayers, we must find the $k$ that solves

$$
\alpha\left(1+\frac{1-\alpha}{\alpha} \frac{\hat{N}_{2}}{N_{1}}\right)\left[\left(1-\hat{k}^{\text {stayer }}\right) w_{2} T_{2}\right]^{\alpha}\left(\frac{A}{\hat{N}_{2}}\right)^{1-\alpha}=\left(w_{1} T_{1}\right)^{\alpha}\left(\frac{A}{N_{1}}\right)^{1-\alpha}
$$

Rearranging terms,

$$
-\ln \left(1-\hat{k}^{\text {stayer }}\right)=\ln \frac{w_{2} T_{2}}{w_{1} T_{1}}-\frac{1-\alpha}{\alpha} \ln \frac{\hat{N}_{2}}{N_{1}}+\frac{1}{\alpha} \ln \left(\alpha+(1-\alpha) \frac{\hat{N}_{2}}{N_{1}}\right) .
$$


We can now relate the compensating variation with a land market to the compensating variation without a land market:

$$
-\ln \left(1-\hat{k}^{\text {stayer }}\right)=-\ln \left(1-k^{\text {stayer }}\right)-\frac{(1-\alpha)}{\alpha} \ln \frac{\hat{N}_{2}}{N_{2}}+\frac{1}{\alpha} \ln \left(\alpha+(1-\alpha) \frac{\hat{N}_{2}}{N_{1}}\right)
$$

Thus, a rural stayer's compensating variation with a land market is the compensating variation without the land market, plus the difference in utility between the two states of the world driven by the difference in the migration response to the program, plus a term that accounts for the rents the stayers collect from the movers.

Recall from Proposition 1 that $\hat{N}_{2}<N_{2}$. Equation 19 thus implies the following:

Proposition 2. Rural incumbents' welfare gain from the program is higher when there is a land market.

Proof. Since $\hat{N}_{2}<N_{2}$ and $\alpha \in(0,1)$, the second term in $(19)$ is strictly positive. Since $\hat{N}_{2} \geq N_{1}$, the third term is weakly positive. Therefore, $-\ln \left(1-\hat{k}^{\text {stayer }}\right)>-\ln \left(1-k^{\text {stayer }}\right)$, which implies $k^{\text {stayer }}<\hat{k}^{\text {stayer }}$.

Proposition 2 is our second main theoretical result. When there is a market for the local, rival publicly provided good, the gain for rural incumbents is larger than when there is no market for this good.

If there are any movers, they have $\hat{\bar{\epsilon}}_{2} \leq \epsilon_{i}<\bar{\epsilon}_{1}$; in addition, holding $\epsilon_{i}$ fixed, a stayer has higher welfare than a mover in period 2 since $r_{2}>r_{1}$. Therefore, stayers' compensating variation is strictly greater than movers' compensating variation and, similar to the no- 
markets case, we have

$$
0 \leq-\ln \left(1-\hat{k}_{i}^{\text {mover }}\right)<-\ln \left(1-\hat{k}^{\text {stayer }}\right)
$$

The aggregate value of the compensating variation for consumers thus satisfies

$$
N_{1} \hat{k}^{\text {stayer }} w_{2} T_{2} \leq \hat{C V}<\hat{N}_{2} \hat{k}^{\text {stayer }} w_{2} T_{2}
$$

Equation 20 is important because it indicates that even if all markets exist, we do not need price data to compute welfare bounds. This is a useful result in settings where population and income can be measured but high-quality land price data are difficult to come by 20

\section{Comparing welfare bounds with and without a land market}

We have shown that incumbents enjoy higher welfare gains when there is a market for land. What about aggregate welfare gains across these rural areas? The lower bound in the no-markets case (16) is strictly lower than the lower bound in the markets case (21) because $k^{\text {stayer }}<\hat{k}^{\text {stayer }}$. However, the upper bounds cannot be similarly ordered: The upper bound on welfare could be larger in the no-markets case if there is a very large population response to

\footnotetext{
${ }^{20} \mathrm{We}$ can, of course, use land price information if there are land markets and if these prices are observed. In Appendix A1, we show that in equilibrium, $\hat{r}_{2}=[(1-\alpha) / \alpha] \hat{N}_{2} w_{2} T_{2} / A$. Substituting this result into (18), and assuming that we also observe a period 1 land price $\hat{r}_{1}$ such that the period 1 population is a market equilibrium, the compensating variation for a rural stayer can be expressed as

$$
-\ln \left(1-\hat{k}^{\text {stayer }}\right)=\frac{1}{\alpha} \ln \frac{w_{2} T_{2}}{w_{1} T_{1}}-\frac{1-\alpha}{\alpha} \ln \frac{\hat{r}_{2}}{\hat{r}_{1}}+\frac{1}{\alpha} \ln \left(\alpha+(1-\alpha) \frac{\hat{r}_{2}}{\hat{r}_{1}}-(1-\alpha) \frac{w_{2} T_{2}}{w_{1} T_{1}}\right) .
$$
}


the infrastructure program and if congestion due to the lack of a land market does not reduce stayers' welfare too much. Alternatively, the upper bound on welfare could be smaller in the no-markets case if there is a small population response and yet congestion greatly reduces stayers' welfare. Which of these outcomes applies will depend on the parameters $s$ (that affects the migration response to the program) and $\alpha$.

\section{F. Extension: infrastructure as an amenity}

So far, we have assumed that the rural electrification program affects communities by raising incomes. This makes sense in the empirical setting of rural household electrification in South Africa. We can easily modify the model to allow electrification to also be an amenity, with no impact on our central propositions.

Assume that at the same time electrification raises incomes, it also raises $A_{1}$ to $A_{2}$, increasing the supply of local public goods. Intuitively, we should see more in-migration toward electrifying areas, as these places are now better places to live in for two reasons: higher incomes and more amenities. We can see this by looking at the labor supply equations (7) and (11): with a higher value of $A_{2}$ on the right-hand side of each equation, the cutoff value for the preference shock $\epsilon$ is lower, which in turn means that more people are willing to live in the rural area after the program relative to before. It is still the case that in equilibrium, there is more migration in the no land markets case than in the land markets case (i.e., Proposition 1 still holds).

The compensating variation for rural stayers also adjusts if electrification has an amenity value. Since $A_{2}>A_{1}$, the amenity stock no longer cancels out of expressions for 
compensating variation. Equation $(13)$ becomes

$$
-\ln \left(1-k^{\text {stayer }}\right)=\ln \frac{w_{2} T_{2}}{w_{1} T_{1}}-\left(\frac{1-\alpha}{\alpha}\right)\left(\ln \frac{N_{2}}{N_{1}}-\ln \frac{A_{2}}{A_{1}}\right)
$$

Similarly, equation $(18)$ becomes

$$
-\ln \left(1-\hat{k}^{\text {stayer }}\right)=\ln \frac{w_{2} T_{2}}{w_{1} T_{1}}-\left(\frac{1-\alpha}{\alpha}\right)\left(\ln \frac{\hat{N}_{2}}{N_{1}}-\ln \frac{A_{2}}{A_{1}}\right)+\frac{1}{\alpha} \ln \left(\alpha+(1-\alpha) \frac{\hat{N}_{2}}{N_{1}}\right)
$$

This change effectively reduces the negative impact of migration on welfare: The congestion effect is moderated by the fact that the new infrastructure has also increased the supply of amenities. Because the difference in the compensating variation for rural stayers in the land markets and no land markets cases is not affected by this constant positive shock to $A$, Proposition 2 also continues to hold: Rural incumbents' welfare gain from the program is still higher when there is a land market.

While the central insights from our model do not change, we would need additional data on the response of $A$ to the program to empirically estimate welfare gains from an infrastructure program when infrastructure is also an amenity.

\section{G. Extension: decreasing returns to scale in production}

In some settings, it may be appropriate to allow production to have decreasing, rather

than constant, returns to scale. This adaptation also does not change the qualitative results in our model. To see this, assume that firms in the rural area are perfectly immobile, operate a decreasing returns to scale aggregate production function $F$, and sell output on a world 
market. Labor markets are competitive, and so the wage in the rural areas is

$$
w_{t}=F^{\prime}\left(T_{t} N_{t}\right)
$$

where $N_{t}$ is the population in the rural area in period $t$. Capital, land, and other amenities do not enter in the production function, except implicitly as the source of decreasing returns. We assume that $F^{\prime}>0, F^{\prime \prime}<0$, and for all $x, F^{\prime}(x)+x F^{\prime \prime}(x)>0$. This final assumption implies that the wage bill rises as labor inputs rise, so that profits are not unbounded as firms expand.

We can substitute the wage expression into the consumers' budget constraint, into their indirect utility functions in equilibrium, and into the two labor supply equations that determine equilibrium population in the post-program period, (7) and (11). The formulae for the compensating variation for consumers and the welfare bounds for this compensating variation remain the same in both the land market and no land market settings.

This adaptation does not affect the conclusions of Propositions 1 and 2 from our simple model. It is still the case that there is more migration in equilibrium without land markets relative to the case with land markets, and rural incumbents still benefit more from the program when there is a land market. However, relative to the case of constant returns to scale, decreasing returns to scale imply less overall migration in both the land markets and no land markets cases. This is because the assumption introduces another margin of adjustment to the program: wages. If workers become more productive with the infrastructure, they inelastically supply more effective units of labor $(T \times N)$ to the market, and so earnings 
increase. However, because $F^{\prime \prime}<0$, equilibrium wages fall with this additional labor input. So although this new infrastructure has raised the utility gain of living in the rural area relative to the urban area, this increase is smaller than it would have been under constant returns to scale. Allowing wages to fall as effective labor inputs rise therefore reduces the incentive to move toward the rural area.

The assumption of decreasing returns to scale has two implications for quantitative estimation of the welfare bounds of the program. First, the migration response to the program would be smaller than under the assumption of constant returns to scale, but none of our formulae for compensating variation of movers and stayers would change. Second, because there would now be positive profits, we would need to keep track of these profits to compute aggregate welfare from the program. If we assumed that firm owners do not live in the rural areas, then we would need to add aggregate post-program profits to both the upper and lower bounds of equations (16) and (21). If instead we assumed that firm owners are rural incumbents, then firm profits would appear in the budget constraint of these incumbents in (4) and (8). In both the land markets and no land markets cases, we would then need to have a credible, causal estimate of the impact of electrification on total income (earnings plus profits) among incumbents to compute accurate measures of the compensating variation.

\section{H. Extension: adding urban welfare to the model}

Up to this point, we have assumed that utility in the urban area is fixed at $\bar{U}$ no matter how many people live there. We now consider how our results would change if the 
urban area were subject to either congestion effects of the same type as we model for the rural area or agglomeration benefits that raise welfare when population is higher.

\section{Urban congestion effects}

First, consider congestion effects in the urban area. We assume that urban residents, like rural residents, get utility from consumption $c$ and a public good $a$. Since $\epsilon_{i}$ reflects the relative preference for living in the rural area, the utility of living in the urban area is given by $U_{u}(c, a)=c^{\alpha} a^{1-\alpha}$ for all consumers. We assume that congestion changes only the allocation of the public good in the urban area, not the urban wage or time endowment. We also assume that neither the urban nor the rural area has a land market; otherwise, we would need to keep track of people who own land and collect rent in one area while living in the other 21

In Appendix A2, we show that allowing for congestion in urban areas does not change the basic form of the rural labor supply function. However, urban congestion does reduce the migration response to the rural infrastructure program, because when there is an urban congestion externality, any program-induced migration from the city to the countryside makes cities more attractive.

As before, in calculating welfare effects, we can distinguish between rural stayers and rural movers, and the welfare impacts of rural infrastructure for these two groups continue to

\footnotetext{
${ }^{21}$ The assumption of no urban land market is extreme - but if we included such a market, then the increase in welfare associated with reduced congestion would be smaller than if there were no urban land market. Therefore, the welfare effect of a rural infrastructure program that is calculated while entirely ignoring the urban area provides a lower bound on the true effect of the program, whereas the welfare effect calculated by including an urban area and assuming no operating urban land market, as we do in this section, provides an upper bound on the true effect of the program.
} 
be as given in equations $(13)$ to $(16)$. But we now must also calculate the welfare impact on urban stayers, who have a welfare gain from the rural infrastructure program because the resulting out-migration from urban areas means that urban stayers experience less congestion. Urban stayers' compensating variation as a percentage of consumption satisfies

$$
\ln \left(1-k^{u, \text { stayer }}\right)=\frac{1-\alpha}{\alpha} \ln \frac{N_{u, 2}}{N_{u, 1}}
$$

The total compensating variation across all individuals is now

$$
\begin{aligned}
C V^{\text {rural }+ \text { urban }} & =\sum_{\text {rural stayers }} k^{\text {stayer }} w_{2} T_{2}+\sum_{\text {movers }} k_{i}^{\text {mover }} w_{2} T_{2}+\sum_{\text {urban stayers }} k^{u, \text { stayer }} w_{u} T_{u} \\
& =\sum_{\text {rural stayers }} k^{\text {stayer }} w_{2} T_{2}+\sum_{\text {movers }} k_{i}^{\text {mover }} w_{2} T_{2}+N_{u, 2} w_{u} T_{u}\left[1-\left(\frac{N_{u, 2}}{N_{u, 1}}\right)^{\frac{1-\alpha}{\alpha}}\right] .
\end{aligned}
$$

Thus, urban congestion effects would raise both the upper and lower bounds of the total compensating variation of the program by the product of post-program urban income $N_{u, 2} w_{u} T_{u}$

and a congestion adjustment $1-\left(\frac{N_{u, 2}}{N_{u, 1}}\right)^{\frac{1-\alpha}{\alpha}}$. If we had data on the population in urban areas (which we do not in the South African case), we could estimate this quantity by the same methods as we use to estimate the compensating variation assuming that urban utility is constant.

\section{Urban agglomeration effects}

Urban agglomeration effects have the opposite consequence from congestion effects: As people leave the urban area, it becomes less attractive. The literature has identified a 
variety of reasons why this might happen, including lower wages (if high population raises labor productivity) or the reduced availability of cultural amenities. We do not attempt to model these effects in detail but note only that they would reduce the total compensating variation of the program below what we show above. Therefore, if there are urban agglomeration effects, all of our estimates give an upper bound for the compensating variation of a rural infrastructure program.

\section{A note on generality}

Our stylized model is adapted to deal with the specifics of the empirical setting of household electrification in rural South Africa. In a different empirical setting, different features could require alternative functional forms or different assumptions about the way in which the spatial investment affects the local economy. For example, a new road might directly affect production, which was not the case for household electrification. Nevertheless, the base components of our approach remain general: Migration responds to new infrastructure and this response results in crowding of amenities that are in inelastic supply. Because migration (or population change) is much more easily measured than land rents, well-estimated migration and income elasticities can be used to create welfare bounds for more complete evaluation of spatial investments. We next turn to implementing our welfare bounds for rural electrification in South Africa.

\section{Empirically implementing the welfare bounds}

Because the South African context we study does not have markets for land, we estimate the rural electrification program's effect on rural consumer welfare using the bounds 
given in (16) for the case of no land markets. The formula for the bounds shows that we can estimate this welfare impact if we know the parameter $\alpha$ and have estimates of the program's effect on income $\left(w_{2} T_{2} / w_{1} T_{1}\right)$ and population $\left(N_{2} / N_{1}\right)$. The basic idea is that as long as we have causal estimates of the impact of an infrastructure program on incomes and population, we do not need any data on local land prices, regardless of whether there is a market for land.

\section{A. Estimating income and population impacts of rural electrification}

We estimate the income and population effects of the rural electrification program from the following system of equations, which is the same specification as Dinkelman (2011) and we used in (1a) to estimate effects on other variables:

$$
\begin{gathered}
\Delta \ln \left(w_{j d t} T_{j d t}\right)=\beta_{1}+\beta_{2} \Delta I_{j d t}+\beta_{3} X_{j d 0}+\beta_{d}+\Delta u_{j d t}^{w T}, \\
\Delta \ln \left(N_{j d t}\right)=\gamma_{1}+\gamma_{2} \Delta I_{j d t}+\gamma_{3} X_{j d 0}+\gamma_{d}+\Delta u_{j d t}^{N} .
\end{gathered}
$$

The parameters $\beta_{1}$ and $\gamma_{1}$ reflect common trends in income and population across all communities, whether or not they receive the infrastructure program, while the parameters $\beta_{2}$ and $\gamma_{2}$ are the effects of the infrastructure program on income and population, $X_{j d 0}$ represents baseline characteristics, $\beta_{d}$ and $\gamma_{d}$ represent district-specific trends, and the residuals $u_{j t}^{w T}$ and $u_{j t}^{N}$ represent all other factors affecting income and population 22 Thus, in the

\footnotetext{
${ }^{22}$ Empirically, equation $(27 \mathrm{~b})$ estimates the relative increase in population in an electrified rural district compared with a non-electrified rural district. In our setting, only a small fraction of internal migration is rural-to-rural migration (Cornwell and Inder, 2004 Reed, 2013, Van der Berg et al., 2002), and so we are not too worried about spatial spillovers between rural areas in our sample.
} 
no-markets case, the compensating variation for a stayer from equation (13) is

$$
-\ln \left(1-k^{\text {stayer }}\right)=\beta_{2}-\frac{1-\alpha}{\alpha} \gamma_{2}
$$

We obtain consistent estimates of $\beta_{2}$ and $\gamma_{2}$ from system IV-GMM regressions of equations (27) that use land gradient as an instrument for infrastructure placement and account for possible correlation of residuals across equations. 23

Since we want to aggregate the compensating variation across individuals in equation (15) to estimate the total monetary value of the program, we need to know $w_{2} T_{2}$, the postprogram income in communities that receive the program. We can estimate $w_{2} T_{2}$ from a regression of $I_{j d 2} \times\left(w_{j d 2} T_{j d 2}\right)$ on $I_{j d 2}$; this regression is estimated jointly with the system 27) so that standard errors account for the possible covariance between estimates of $\beta_{2}, \gamma_{2}$, and $w_{2} T_{2}$.

We also need to know $N_{1}$ and $N_{2}$. In the model, $N_{1}$ is the rural area's pre-program population and $N_{2}$ is the rural area's post-program population (in the no-markets case). We can observe $N_{2}$ directly: It is the total population in areas that received the infrastructure

\footnotetext{
${ }^{23}$ Allowing infrastructure to also be an amenity would require estimating a third equation in the system to capture the causal effect of electrification on an index of local amenities. This estimate would then be included into the estimate of 28$\rangle$, following 222 . If we allowed decreasing returns to scale in production, we would need to add a profit equation to the system and estimate the impact of electrification on profits. This estimate would then be added to the upper and lower bounds of our estimate of the compensating variation for consumers if firm owners were not rural incumbents. If firm owners were rural incumbents, we would include this profit response as part of the first term in (28) before creating the aggregate welfare bounds.
} 
program, after the program is implemented, or

$$
N_{2}=\sum_{j: \text { received program }} N_{j 2}
$$

Since we have population data from a census, $N_{2}$ is not a random variable and need not be estimated jointly with the other parameters.24 Because other factors besides the infrastructure program may also be changing the rural population, we cannot calculate $N_{1}$ from the observed pre-program populations, $N_{j 1}$. Rather, $N_{1}$ should be the counterfactual population that the rural area would have had at $t=2$ if it did not get the program. That is, for a community $j$ that received the program, we should set

$$
N_{1}(j)=N_{j 2} / \exp \left(\gamma_{2}\right)
$$

The total population in treated areas, if the program had not taken place, is thus

$$
N_{1}=\sum_{j: \text { received program }} N_{1}(j)=\sum_{j} \frac{N_{j 2}}{\exp \left(\gamma_{2}\right)}=\frac{N_{2}}{\exp \left(\gamma_{2}\right)}
$$

Putting together all of our results, the empirical bounds on the compensating variation

\footnotetext{
${ }^{24}$ If the population data came from a survey or from a randomly sampled subset of treated communities, then $N_{2}$ would need to be estimated jointly with the rest of the system using a regression analogous to the mean post-program income regression.
} 
in the no-markets case can be estimated using

$$
\frac{N_{2}}{\exp \left(\gamma_{2}\right)}\left[1-\exp \left(-\beta_{2}+\frac{1-\alpha}{\alpha} \gamma_{2}\right)\right] w_{2} T_{2} \leq C V<N_{2}\left[1-\exp \left(-\beta_{2}+\frac{1-\alpha}{\alpha} \gamma_{2}\right)\right] w_{2} T_{2}
$$

Conditional on $\alpha$ and $N_{2}$, standard errors for these bounds are obtained from the joint variance-covariance matrix of the estimators of $\beta_{2}, \gamma_{2}$, and $w_{2} T_{2}{ }^{25}$

A similar formula expressing the welfare bounds as a function of $\alpha, \beta_{2}, \gamma_{2}, w_{2} T_{2}$, and $N_{2}$ — derived from $(18)$ - would apply for the markets case. That case does not apply here because the context we study does not have land markets. However, even in contexts where land markets exist, calculations based on population and income may be more attractive than calculations based on land prices because collecting good data on population and income may be more feasible than collecting good data on land prices.26

\section{B. Two ways to estimate $\alpha$}

The last piece we need before computing the welfare bounds is an estimate of $\alpha$.

As $\alpha \rightarrow 1$, consumer preferences shift toward the consumption good and away from the local, rival publicly provided good (land). A weak preference for the public good minimizes the negative congestion impact of migration and moves the welfare bounds for the markets

\footnotetext{
${ }^{25}$ Point estimates and standard errors for model parameters come from jointly estimating equations (27) and a regression of $I_{j d 2} \times\left(w_{j d 2} T_{j d 2}\right)$ on $I_{j d 2}$. We combine these point estimates with $N_{2}$ and a chosen $\alpha$ to construct the compensating variation for stayers, $k$, in equation 28 and the upper and lower bounds on welfare in equation (16). Since $k$ and the welfare bounds are nonlinear combinations of model parameters, we use the delta method to construct standard errors. We have also constructed Anderson-Rubin confidence intervals for $\beta_{2}$ and $\gamma_{2}$ that are robust to weak instruments. Our IV point estimates fall within these confidence intervals.

${ }^{26} \mathrm{~A}$ caveat is that these estimates also need to be reasonably precise for the welfare bounds to be informative.
} 
and no-markets cases toward each other. In the limit, if consumers did not care for land (or schooling or health services) at all, the welfare bounds would be identical — and equal to the program's income effect — regardless of whether there were a market for these goods.

Alternatively, as $\alpha \rightarrow 0$, consumer preferences shift toward land (or other publicly provided goods) and away from the consumption good, and the migration response to the program gains a larger weight in the welfare bounds. In both the market and no-markets cases, the welfare bounds get wider, admitting a larger range of possible effects of the program.

Clearly, then, the choice of $\alpha$ parameter strongly affects the welfare calculation. We calibrate a sensible value for this parameter using two different strategies that turn out to suggest similar values.

Our first strategy is to assume that self-reported life satisfaction in a survey is monotonically related to a household's utility from consumption and public goods. Specifically, we assume that

$$
U_{i}=\left[U\left(c_{i}, a_{i}\right)\right]_{1}^{\theta} \exp \left(\theta_{0}+v_{i}\right)
$$

where $U_{i}$ is household $i$ 's self-reported life satisfaction, $U\left(c_{i}, a_{i}\right)=c^{\alpha} a^{1-\alpha}$, and $\exp \left(v_{i}\right)$ is a multiplicative measurement error. Then

$$
\ln \left(U_{i}\right)=\theta_{0}+\theta_{1} \alpha \ln \left(c_{i}\right)+\theta_{1}(1-\alpha) \ln \left(a_{i}\right)+v_{i}
$$

We estimate (34) on a data set of rural African households interviewed in 1993, prior to 
the implementation of the electrification program ${ }^{27}$ We use measures of monthly income to proxy for consumption and measures of district population density to construct a measure of $a_{i}$ (which is the inverse of population density). Our outcome measure is the (log of the) household's response to the following question: "Taking everything into account, how satisfied is the household with the way it lives these days?" and where answers were given on a scale of one to five. We restrict the value of $\alpha$ to lie between 0 and 1 by specifying that $\alpha=\exp (q) /(1+\exp (q))$ for some parameter $q$ and estimating $\theta_{0}, \theta_{1}$, and $q$ by nonlinear least squares.

Summary statistics for the life satisfaction data are in Appendix A4, and results from estimating (34) are in Table 3. We find a point estimate for $\alpha$ of 0.991 . This value does not depend on any particular model for migration, nor on any assumptions about the market for land, nor on estimates of the income and population effects of the infrastructure investments. (Nonetheless, our estimation of $\alpha$ is not entirely consistent with our migration model because we have ignored the additive preference for the rural area $\epsilon_{i}$.) This large a value of $\alpha$ implies that congestible publicly provided goods have only a very small impact on utility. Still, when we use this value for $\alpha$ in our welfare calculations, we will find that migration responses remain large enough to appreciably change the evaluation of the placebased program in South Africa.

Our second strategy for calibrating $\alpha$ uses our migration model to derive a lower bound for the parameter. Equation $(32)$ shows that, for any given income and population

\footnotetext{
${ }^{27}$ The data are commonly known as the SALDRU data and are obtained from the first Living Standards Measurement Study-type household survey conducted in South Africa in 1993. This is the only year in the 1990s for which there exists a question on life satisfaction.
} 
elasticities, the welfare impact of a program is negative when $\alpha$ is sufficiently small. However, in equilibrium in our model, any program that raises incomes cannot reduce total welfare. Thus, the lower bound for $\alpha$ is the value that makes the program's estimated welfare impact zero. In the no-markets case, the welfare effect of the program is zero when $k^{\text {stayer }}$ is zero, or when

$$
\alpha=\frac{\ln \left(N_{2} / N_{1}\right)}{\ln \left[\left(w_{2} T_{2}\right) /\left(w_{1} T_{1}\right)\right]+\ln \left(N_{2} / N_{1}\right)}=\frac{\gamma_{2}}{\beta_{2}+\gamma_{2}} .
$$

The expression for the markets case would be derived in the same way, under the condition

that $\hat{k}^{\text {stayer }}$ is zero (that is, using $(18)$ and solving for the value of $\alpha$ that sets the right-hand side of this equation to zero).

Given estimates of $\beta_{2}$ and $\gamma_{2}$, we estimate the highest lower bound for $\alpha$ is 0.979 . Our satisfaction-based point estimate of 0.991 is thus consistent with the model-implied lower bound. However, the lower bound rules out much of the confidence interval for $\alpha$ implied by the standard error of the satisfaction-based estimate. Therefore, in constructing standard errors for our welfare bounds, we treat the point estimate as the exact value of $\alpha$ and do not account for estimation error in $\alpha 28$

\section{Welfare bounds on rural electrification in South Africa}

Table 4 presents the main results for key parameters and our estimated bounds on the welfare impact of the electrification program.

\footnotetext{
${ }^{28}$ Taking the standard error of the estimate of $\alpha$ into account in computing the welfare bounds would create "bounds on bounds" that would be less informative than using the point estimate for $\alpha$. We note that while our approach gets around the thorny issue of having no data on land prices, the usefulness of our approach relies on having precisely estimated causal effects of the impact of a program on income and migration as well as precise estimates of $\alpha$.
} 
First, in Panel A, we present consistent estimates of the overall employment and population impacts of rural electrification. We combine employment data for men and women and find that electrification raises the overall employment rate by 8.3 percentage points, although this change is not significantly different from zero ( $t$-statistic of 1.63) ${ }^{29}$ As described in Dinkelman (2011), electrification likely increases employment in rural KZN through some combination of releasing time from home production into market work and enabling people to make new jobs for themselves in self-employment or small enterprise. There is also substantial population growth in electrifying areas using the IV results. This was the population increase underlying the crowding of households and schools in Table 2 .

To compute welfare effects, we value employment gains and migration crowd-out in terms of local monthly earnings. Since the Census does not contain measures of hours of work, wages, or income, we use community-level data from the 2001 October Household Survey to construct average post-program monthly earnings for African workers in 44 areas and assign these averages to each of the 1,816 census communities. Average monthly earnings in 2001 were just over ZAR1,200, or 285USD in 2001 dollars according to the purchasing power parity reported in the Penn World Table (Heston, Summers, and Aten, 2011). Using a different data set and an alternative identification strategy, Dinkelman (2011) shows that wages do not rise significantly in response to the new infrastructure. If all response is on the extensive margin, then employment growth (valued by average earnings) gives us the total income gain associated with the program.

\footnotetext{
${ }^{29}$ Separately estimating male and female employment effects, Dinkelman (2011) finds that female employment rises by 9 percentage points in electrified relative to non-electrified areas, and this result is statistically significant at the $10 \%$ level. There are no significant impacts on male employment in the Census data.
} 
Panel B of Table 4 calculates bounds on the compensating variation associated with the program. We use the no-markets version of the compensating variation in (13) to estimate values for $k$ - the fraction of post-program income that a rural stayer would need to give up in order to keep utility the same before and after the program. We present these estimates ignoring the migration response in column 1 and then taking account of the migration response in column 2. Column 2 bounds are computed under the assumption that $\alpha=0.991$; in other words, only $0.9 \%$ of utility comes from local publicly provided goods such as land or schooling, and 99.1\% from consumption.

Under the assumptions of our model, rural stayers would be willing to give up $8 \%$ of their income to keep the program. We monetize this compensating variation by multiplying $k$ by the average monthly earnings in treated areas post-electrification, weighted by the increased employment in these areas ${ }^{30}$ The monthly value of the compensating variation for an average rural stayer is about ZAR17 ignoring the migration effect. That is, individuals would be willing to give up ZAR17 per month to retain the program.

In contrast, when we include the migration impact, just over $40 \%$ of this welfare gain disappears. The compensating variation of the program is only $0.9 \%$ of income, assuming $\alpha=0.991$. The value of this is only ZAR9.9 per month.

Finally, we compute the lower and upper bounds on the total monetary value of the compensating variation using information about $N_{2}$ and $N_{1}$ - the post-program population

\footnotetext{
${ }^{30}$ Specifically, we multiply our estimate of $k$ by 213.47 taking into account the error variance of this estimate (standard error 25.48). This number is the coefficient on the treatment indicator in the third equation of our IV system: an IV regression of the interaction of treatment, post-program employment levels, and monthly earnings (from an external data set) on a treatment indicator and district fixed effects.
} 
and the counterfactual population without the program. As shown in the final two rows of Table 4, we find that the program was worth between ZAR127,623 and ZAR6.3 million per month in all treated areas if migration is ignored. When we add in the migration effects, the bounds shrink to between about ZAR74,000 and ZAR3.6 million per month. Given the standard errors on these bounds, we can reject zero impact of the program when migration is not included. However, once we include the effects of congestion in local, rival publicly provided goods induced by the higher population, it is no longer possible to reject that the program had zero impact on overall welfare. This is notable: Even when people do not value local public goods very highly ( substantially diminished in the presence of migration.

If urban areas experience congestion externalities, then migration toward rural areas generates additional benefits from the rural electrification program that we do not capture. These gains could shift aggregate welfare bounds away from zero. Looking at our lower bound welfare estimate, we see that the magnitude of these congestion effects would have to be at least ZAR 7,198,082 (the lower bound of the 95\% confidence interval on the welfare lower bound in the final column of Table 4 to shift the lower bound on welfare above zero. This gain could only be generated by reductions in population in urban areas. Since the number of people living in urban areas in South Africa over this period increased by 15\% (Statistics South Africa, 1996, 2001), we do not think such magnitudes are plausible ${ }^{31}$ Leaving urban congestion effects out of the analysis is therefore unlikely to substantially

\footnotetext{
${ }^{31}$ To see this, we can construct a back-of-the-envelope estimate of 25 for the compensating variation for urban stayers. This magnitude will be negative unless $N_{u, 2} \leq N_{u, 1}$.
} 
change our estimates of the welfare bounds. Of course, if there are positive agglomeration externalities in urban areas, then the effect of migration from urban to rural areas would shift the welfare bounds down even further.

\section{Conclusions}

Our paper is motivated by the idea that any place-based program may induce migration responses, that such migration responses could lead to important congestion in inelastically supplied local publicly provided goods, and that this migration and congestion should be accounted for in evaluations of spatial investments. We use the South African example of rural household electrification to illustrate these ideas. Furthermore, we show how the welfare effects of spatial programs can be estimated even in settings where land markets do not exist or land price data are scarce.

The paper adapts a spatial model of location choice to the rural South African context. This is a setting in which substantial migration and related congestion in local homes and schools occurred in response to new infrastructure. We use the model to show three things. First, ignoring migration responses to a spatial program may lead researchers to miscalculate the program's welfare benefits to incumbents. Second, when there are no markets for important local, congestible publicly provided goods (such as land, schools, or health care), the migration response to a spatial program is larger, leading to greater congestion in inelastically supplied publicly provided goods. This story of the tragedy of the commons has important implications for evaluating location-based programs.

Third, accounting for migration responses is possible by combining the structure of a 
model suited to the specific institutional environment with consistent estimates of the income and population effects of the spatial program. We show how to estimate upper and lower bounds for the compensating variation of the rural electrification investment using income and population elasticities and an estimate of preferences for consumption relative to a local publicly provided good. In this South African case, taking migration into account reduced the compensating variation from the rural electrification program by just over $40 \%$.

Although migration is a key component of any spatial equilibrium model, the migration response to spatial investments appears to have fallen off the agenda of development economists. Future urbanization and development of rural areas in poor countries is likely to bring migration and related congestion issues to the fore once more ${ }^{32}$ Our approach complements traditional approaches to valuing the impact of place-based programs that rely on measures of land rents, which are often unavailable in developing countries.

Our work carries several caveats: We do not allow for dynamic effects of programs, for general equilibrium effects on the national price level from local programs, or for agglomeration externalities from changes in population density in either the area that receives a program or areas that send migrants. In addition, our welfare analysis ignores the issue of how and where to raise tax revenue to pay for a local program (although in many poor countries, international donors may be the most common source of funds for such projects). Broadening the analysis along these dimensions would further sharpen our understanding of how migration changes the costs and benefits of place-based programs in developing coun-

\footnotetext{
${ }^{32}$ More than three-quarters of the urban population in Africa live in slums; future urbanization trends in these areas will continue to put pressure on existing urban areas (Cohen, 2006).
} 
tries. 
Table 1: Summary statistics

\begin{tabular}{lrrrrr}
\hline & $N$ communities & mean & s.d. & min. & max. \\
\hline Eskom project areas & 1,816 & 0.20 & 0.40 & 0 & 1 \\
Employment rate in 1996 & 1,816 & 0.10 & 0.09 & 0.00 & 0.93 \\
Household density in 1996 & 1,816 & 22 & 30.48 & 1 & 592 \\
Population in 1996 & 1,816 & 1,396 & 1,255 & 149 & 16,415 \\
Household size in 1996 & 1,816 & 3.62 & 0.62 & 2 & 14 \\
Monthly earnings in 2001 ZAR* & 41 & 1,124 & 611 & 299 & 3,890 \\
Number of schools in 1995 & 1,816 & 0.94 & 1.18 & 0 & 11 \\
Number of learners in 1995 & 1,126 & 863 & 700 & 0 & 5,686 \\
Student-teacher ratio in $1995^{\dagger}$ & 1,098 & 39 & 11 & 4 & 116 \\
\hline
\end{tabular}

All non-school-related data are from Dinkelman (2011). See appendix of that paper for original data sources. Unit of observation is the community. *Average monthly earnings are computed from individual-level data (October Household Survey 2001) for African workers using sample weights to compute community-level means. ${ }^{\dagger}$ Data on schools are from the 1995 and 2000 South African School Register of Needs Survey. Data on schools were linked to communities by spatially matching the GPS coordinates of schools in each year with Census community boundaries. 


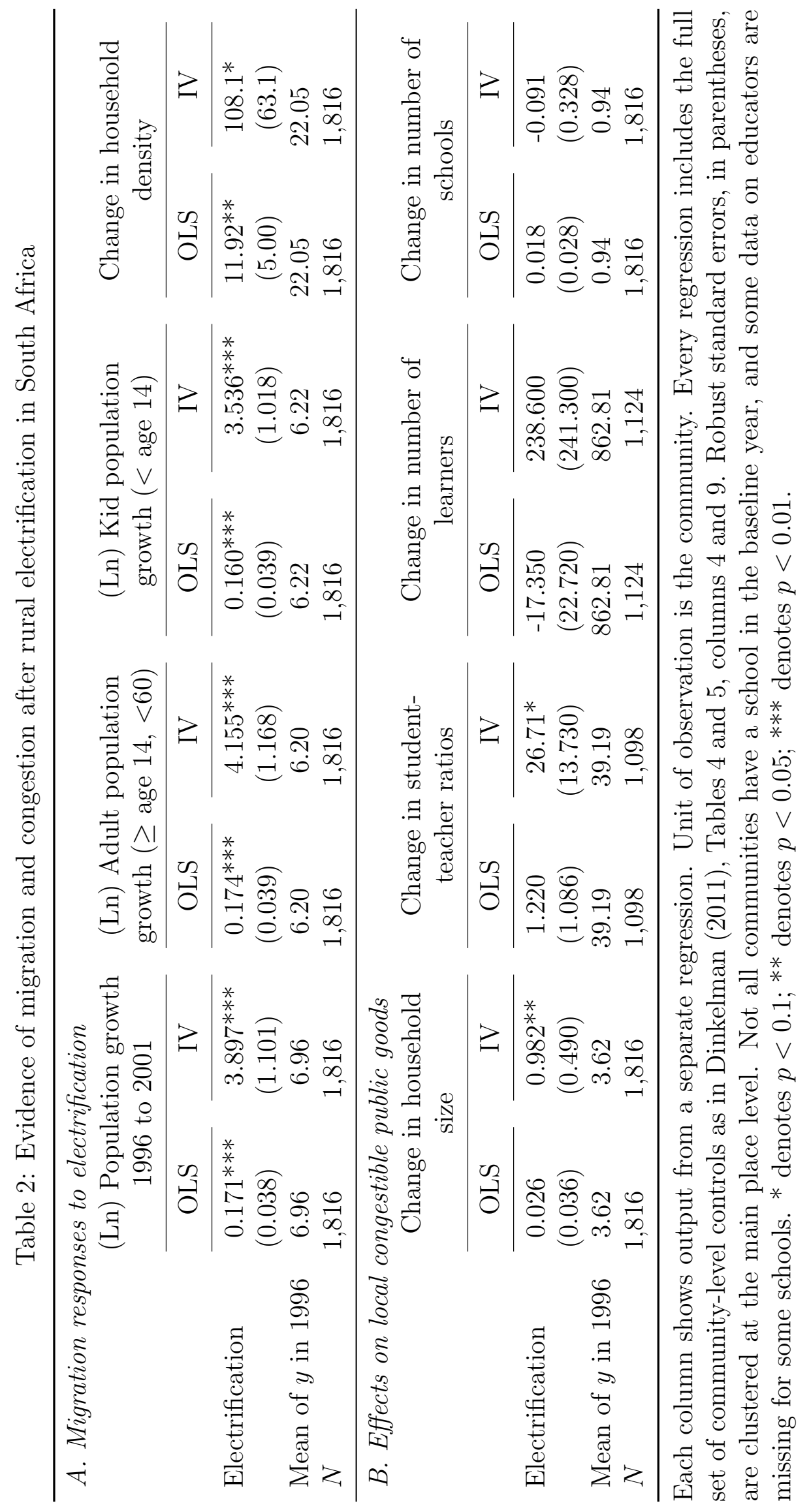


Table 3: Estimation of $\alpha$ from self-reported life satisfaction

\begin{tabular}{lc}
\hline & $\begin{array}{c}(\mathrm{Ln}) \text { self-reported } \\
\text { life satisfaction }\end{array}$ \\
\hline (Ln) income & $0.08^{* * *}$ \\
& $(0.018)$ \\
$(\mathrm{Ln}) 1 /$ population density & 0.00007 \\
& $(0.008)$ \\
Intercept & $0.411^{* * *}$ \\
& $(0.086)$ \\
\hline$\alpha$ & $0.991^{* * *}$ \\
& $(0.101)$ \\
\hline$N$ & 668 \\
$R^{2}$ & 0.028 \\
\hline
\end{tabular}

Unit of observation is the household. Standard errors in parentheses. ${ }^{* * *}$ denotes $p<0.01$. Data are from the 1993 Project for Statistics on Living Standards and Development in South Africa Survey. 


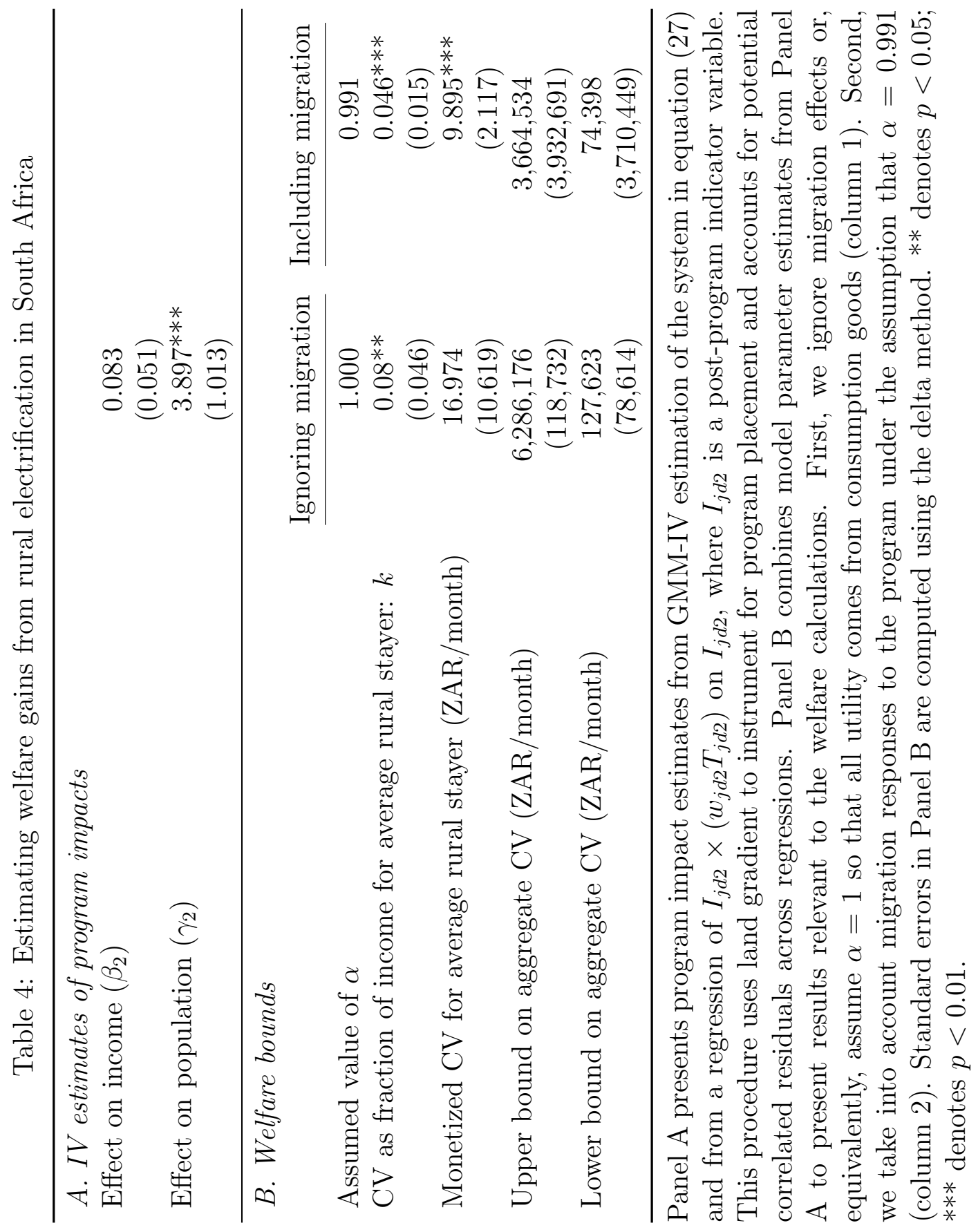




\section{Appendix}

\section{A1. Derivation of indirect utilities when there is a land market}

There are $N_{1}$ stayers and $\hat{N}_{2}-N_{1}$ movers, so market clearing for the local public good (land) requires

$$
N_{1} \hat{a}_{2, \text { stayer }}+\left(\hat{N}_{2}-N_{1}\right) \hat{a}_{2, \text { mover }}=A
$$

Maximization by rural stayers implies

$$
\hat{c}_{2, \text { stayer }}=\alpha\left(w_{2} T_{2}+\hat{r}_{2} \frac{A}{N_{1}}\right), \quad \hat{a}_{2, \text { stayer }}=\frac{1-\alpha}{\hat{r}_{2}}\left(w_{2} T_{2}+\hat{r}_{2} \frac{A}{N_{1}}\right)
$$

while maximization by movers to the rural area implies

$$
\hat{c}_{2, \text { mover }}=\alpha w_{2} T_{2}, \quad \hat{a}_{2, \text { mover }}=\frac{1-\alpha}{\hat{r}_{2}} w_{2} T_{2}
$$

Rural stayers now collect rent from land, while movers must pay rent for (or buy) land. Hence, incumbents enjoy a wealth effect associated with the new infrastructure, if there are any in-migrants and if land (or housing) is inelastic in supply.

Market clearing for land requires

$$
N_{1} \frac{1-\alpha}{\hat{r}_{2}}\left(w_{2} T_{2}+\hat{r}_{2} \frac{A}{N_{1}}\right)+\left(\hat{N}_{2}-N_{1}\right) \frac{1-\alpha}{\hat{r}_{2}} w_{2} T_{2}=A
$$

or

$$
\hat{r}_{2}=\frac{1-\alpha}{\alpha} \frac{\hat{N}_{2} w_{2} T_{2}}{A}
$$


Therefore, the indirect utility of a rural stayer is

$$
\begin{aligned}
\hat{U}_{i 2, \text { stayer }}^{*} & =\max _{\hat{c}_{2, \text { stayer }}, \hat{a}_{2, \text { stayer }}} \hat{c}_{2, \text { stayer }}^{\alpha} \hat{a}_{2, \text { stayer }}^{1-\alpha}+\epsilon_{i} \quad \text { s.t. } \quad \hat{c}_{2, \text { stayer }}+\hat{r}_{2} \hat{a}_{2, \text { stayer }} \leq w_{2} T_{2}+\hat{r}_{2} \frac{A}{N_{1}} \\
& =\alpha^{\alpha}\left(\frac{1-\alpha}{\hat{r}_{2}}\right)^{1-\alpha}\left(w_{2} T_{2}+\hat{r}_{2} \frac{A}{N_{1}}\right)+\epsilon_{i} \\
& =\alpha\left(1+\frac{1-\alpha}{\alpha} \frac{\hat{N}_{2}}{N_{1}}\right)\left(w_{2} T_{2}\right)^{\alpha}\left(\frac{A}{\hat{N}_{2}}\right)^{1-\alpha}+\epsilon_{i}
\end{aligned}
$$

and the indirect utility of a mover to the rural area is

$$
\begin{aligned}
\hat{U}_{i 2, \text { mover }}^{*} & =\max _{\hat{c}_{2, \text { mover }}, \hat{a}_{2, \text { mover }}} \hat{c}_{2, \text { mover }}^{\alpha} \hat{a}_{2, \text { mover }}^{1-\alpha}+\epsilon_{i} \quad \text { s.t. } \quad \hat{c}_{2, \text { mover }}+\hat{r}_{2} \hat{a}_{2, \text { mover }} \leq w_{2} T_{2} \\
& =\alpha^{\alpha}\left(\frac{1-\alpha}{\hat{r}_{2}}\right)^{1-\alpha}\left(w_{2} T_{2}\right)+\epsilon_{i} \\
& =\alpha\left(w_{2} T_{2}\right)^{\alpha}\left(\frac{A}{\hat{N}_{2}}\right)^{1-\alpha}+\epsilon_{i} .
\end{aligned}
$$

\section{A2. Derivation of rural labor supply function when urban utility is added to the model}

This section assumes the basic structure of the spatial equilibrium model and adds urban welfare. The utility of urban residents is given by $U_{u}(c, a)=c^{\alpha} a^{1-\alpha}$, since $\epsilon_{i}$ reflects the relative preference for living in the rural area. Urban congestion changes only the allocation of the public good in the urban area, and we assume no urban land market.

An equilibrium in each period is a consumption choice for each consumer and an assignment of consumers to locations such that each consumer's consumption and location choices maximize utility, taking the rationing of the public good in both urban and rural areas as given. Let $N_{u, 1}$ and $N_{u, 2}$ be the urban population before and after the rural infra- 
structure program is implemented. Also let $w_{u}, A_{u}$, and $T_{u}$ be the urban wage and the urban endowments of public goods and amenities. Then the indirect utility of living in the urban area in period $t \in\{1,2\}$ is

$$
U_{u, t}^{*}=\left(w_{u} T_{u}\right)^{\alpha}\left(\frac{A_{u}}{N_{u, t}}\right)^{1-\alpha}
$$

Thus, $i$ chooses to live in the rural area in period $t$ if and only if

$$
\epsilon_{i} \geq\left(w_{u} T_{u}\right)^{\alpha}\left(\frac{A_{u}}{N_{u, t}}\right)^{1-\alpha}-\left(w_{t} T_{t}\right)^{\alpha}\left(\frac{A}{N_{t}}\right)^{1-\alpha}
$$

The rural labor supply function in period $t$ now becomes

$$
s \frac{2 N_{t}-P}{P}=\left(w_{t} T_{t}\right)^{\alpha}\left(\frac{A}{N_{t}}\right)^{1-\alpha}-\left(w_{u} T_{u}\right)^{\alpha}\left(\frac{A_{u}}{P-N_{t}}\right)^{1-\alpha}
$$

where we have used the fact that $N_{t}+N_{u, t}=P$.

The left-hand side of $\mathrm{A} 10$ is increasing in rural population $N_{t}$, while the right-hand side is decreasing in $N_{t}$ and increasing in $w_{t} T_{t}$. Hence, just as when urban utility was fixed, more people live in the rural area after the infrastructure is built. However, the right-hand side of A10 decreases more rapidly with rural population than the right-hand side of (7), because migration from the city to the countryside now makes the city more attractive in addition to making the rural area less attractive. Therefore, the population response to the rural infrastructure program is smaller if there are congestion effects in the urban area. 


\section{A3. Assignment to electricity project: first-stage regression results}

\begin{tabular}{lc}
\hline Binary outcome & District had electricity project between 1996 and 2001 \\
\hline Land gradient*10 & $-0.077^{* * *}$ \\
& $(0.027)$ \\
Kilometers to grid*10 & -0.011 \\
& $(0.023)$ \\
Household density in $1996^{*} 10$ & $0.013^{* *}$ \\
& $(0.006)$ \\
Kilometers to road*10 & -0.010 \\
& $(0.010)$ \\
Kilometers to town*10 & 0.008 \\
& $(0.016)$ \\
District fixed effects & \\
& \\
$N$ & \\
$R^{2}$ & 1,816 \\
$F$-stat. on instrument & 0.18 \\
Probability $>$ F & 8.26 \\
Mean of Y & 0.00 \\
\hline
\end{tabular}

Table presents coefficients from OLS regression of Eskom Project indicator on community covariates measured in 1996. Robust standard errors clustered at subdistrict level. Significant at $\mathrm{p}<0.01^{* * *}, \mathrm{p}<0.05^{* *}$, or $\mathrm{p}<0.1^{*}$ level. Additional controls include: ten district fixed effects, change in share of households with access to water and flush toilet between 1996 and 2001, share of men and women with high school education in 1996, share of Indian and white households in district in 1996, share of female-headed households in 1996, female/male sex ratio in 1996, share of households below poverty line in 1996. Source: Dinkelman (2011), Table 3, column 4. 


\section{A4. Summary statistics for life satisfaction data}

\begin{tabular}{lcccc}
\hline Variable & Mean & s.d. & Min. & Max. \\
\hline Monthly household income per capita (ZAR) & 154.57 & 165.07 & 0.30 & $1,592.50$ \\
Population density (per square km) & 90.20 & 229.68 & 0.410 & 932.54 \\
Self-reported happiness (1-5 scale) & 2.42 & 1.11 & 1 & 5 \\
\hline Data are from the 1993 Project for Statistics on Living Standards and Development \\
in South Africa (PSLSD), widely known as the SALDRU data. Original survey data \\
are available from DataFirst at the University of Cape Town. Sample is restricted to \\
African households from rural areas of the former KwaZulu-Natal area. We recode \\
the survey self-reported happiness variable to run on a scale of 1 l least satisfied \\
to $5=$ most satisfied.
\end{tabular}

\section{References}

Adams, Martin, Ben Cousins, and Siyabulela Manona. 1999. "Land tenure and economic development in rural South Africa: Constraints and opportunities." Overseas Development Institute Working Paper 125.

Albouy, David. 2009. "What are cities worth? Land rents, local productivity, and the capitalization of amenity values." Working Paper 14981, National Bureau of Economic Research.

Banerjee, Abhijit V., and Esther Duflo. 2007. "The economic lives of the poor." Journal of Economic Perspectives, 21(1): 141-168.

Banerjee, Abhijit, Esther Duflo, and Nancy Qian. 2012. "On the road: Access to transportation infrastructure and economic growth in China." Working Paper 17897, National Bureau of Economic Research.

Black, Sandra E. 1999. "Do better schools matter? Parental valuation of elementary education." Quarterly Journal of Economics 114(2): 577-599.

Briceño-Garmendia, Cecilia, Karlis Smits, and Vivien Foster. 2008. "Financing public infrastructure in sub-Saharan Africa: Patterns and emerging issues." African Infrastructure Country Diagnostic Background Paper 15.

Busso, Matias, Jesse Gregory, and Patrick Kline. 2013. "Assessing the incidence and efficiency of a prominent place based policy." American Economic Review 103(2): 897-947.

Calabrese, Stephen M., Dennis N. Epple, and Richard E. Romano. 2012. "Inefficiencies from metropolitan political and fiscal decentralization: Failures of Tiebout competition." Review of Economic Studies 79(3), 1081-1111. 
Cattaneo, Matias D., Sebastian Galiani, Paul J. Gertler, Sebastian Martinez, and Rocio Titiunik. 2009. "Housing, health, and happiness." American Economic Journal: Economic Policy 1(1), 75-105.

Chetty, Raj, John N. Friedman, Nathaniel Hilger, Emmanuel Saez, Diane Whitmore Schanzenbach, and Danny Yagan. 2011. "How does your kindergarten classroom affect your earnings? Evidence from Project Star." Quarterly Journal of Economics 126(4), $1593-1660$.

Cohen, Barney. 2006. "Urbanization in developing countries: Current trends, future projections, and key challenges for sustainability." Technology in Society 28(1-2): 63-80.

Cornwell, Katy, and Brett Inder. 2004. "Migration and unemployment in South Africa: When motivation surpasses the theory." Monash Econometrics and Business Statistics Working Paper 2/04.

Crépon, Bruno, Esther Duflo, Marc Gurgand, Roland Rathelot, Philippe Zamora. 2013. "Do labor market policies have displacement effects? Evidence from a clustered randomized experiment." Quarterly Journal of Economics 128(2), 531-580.

Davis, Lucas W. 2011. "The effect of power plants on local housing prices and rents." Review of Economics and Statistics 93(4), 1391-1402.

Devoto, Florencia, Esther Duflo, Pascaline Dupas, William Parienté, and Vincent Pons. 2011. "Happiness on tap: Piped water adoption in urban Morocco." Mimeo, Massachusetts Institute of Technology.

Dinkelman, Taryn. 2011. "The effects of rural electrification on employment: New evidence from South Africa." American Economic Review 101(7), 3078-3108.

Donaldson, Dave. Forthcoming. "Railroads of the Raj: Estimating the impact of transportation infrastructure." American Economic Review.

Duflo, Esther, and Rohini Pande. 2007. "Dams." Quarterly Journal of Economics 122(2), 601-646.

Glaeser, Edward L. 2007. "The economics approach to cities." Working Paper 13696, National Bureau of Economic Research.

Glaeser, Edward L. 2008. Cities, agglomeration and spatial equilibrium. Oxford: Oxford University Press.

Hall, Ruth. 2009. Another countryside? Policy options for land and agrarian reform in South Africa. Bellville, South Africa: Institute for Poverty, Land and Agrarian Studies, School of Government, University of the Western Cape. 
Heston, Alan, Robert Summers, and Bettina Aten. 2011. "Penn World Table Version 7.0." Center for International Comparisons of Production, Income and Prices, University of Pennsylvania.

Kremer, Michael, Jessica Leino, Edward Miguel, and Alix Peterson Zwane. 2011. "Spring cleaning: Rural water impacts, valuation, and property rights institutions." Quarterly Journal of Economics 126(1), 145-205.

Lahiff, Edward. 2001. "Land Reform in South Africa: Is it meeting the challenge?" Debating Land Reform and Rural Development Policy Brief, No. 1 September, School of Government, University of the Western Cape.

Lall, Somik V., and Matias Lundberg. 2008. "What are public services worth, and to whom? Non-parametric estimation of capitalization in Pune." Journal of Housing Economics 17(1): 34-64.

Lin, Justin Yifu, and Doerte Doemeland. 2012. "Beyond Keynesianism: Global infrastructure investments in times of crisis." Policy Research Working Paper 5940, World Bank.

Lipscomb, Molly, A. Mushfiq Mobarak, and Tania Barham. 2013. "Development effects of electrification: Evidence from the topographic placement of hydropower plants in Brazil." American Economic Journal: Applied Economics 5(2): 200-231.

Lozano-Gracia, Nancy, Cheryl Young, Somik V. Lall, and Tara Vishwanath. 2013. "Leveraging land to enable urban transformation: Lessons from global experience." Policy Research Working Paper 6312, World Bank.

Mobarak, Mushfiq Ahmed and Mark Rosenzweig. 2014. "Risk, insurance and wages in general equilibrium." Working Paper at http://faculty.som.yale.edu/mushfiqmobarak/ research.html, June.

Moretti, Enrico. 2011. "Local labor markets." In Handbook of labor economics, vol. 4B, ed. Orley Ashenfelter and David Card, 1238-1303. Amsterdam: Elsevier.

Quigley, John M. 2008. "Urbanization, agglomeration, and economic development." In Urbanization and growth: Commission on growth and development, ed. Michael Spence, Patricia Clarke Annez, and Robert M. Buckley, 115-132. Washington, D.C.: World Bank.

Reed, Holly E. 2013. "Moving across boundaries: Migration in South Africa, 1950-2000." Demography 50(1), 71-95.

Roback, Jennifer. 1982. "Wages, rents, and the quality of life." Journal of Political Economy 90(6), 1257-1278.

Rosenzweig, Mark R., and Kenneth I. Wolpin. 1986. "Evaluating the effects of optimally distributed public programs: Child health and family planning interventions." American Economic Review 76(3), 470-482. 
Statistics South Africa. 1996. "Population Census of South Africa 1996, 10\% sample."

Statistics South Africa. 2001. "Population Census of South Africa 2001, 10\% sample."

Tiebout, Charles M. 1956. "A pure theory of local expenditures." Journal of Political Economy 64(5), 416-424.

Udry, Christopher. 2012. "Land tenure." In The Oxford companion to the economics of Africa, ed. Ernest Aryeetey, Shantayanan Devarajan, Ravi Kanbur, and Louis Kasekende, 410-415. Oxford: Oxford University Press.

Usher, Dan. 1977. "Public property and the effects of migration upon other residents of the migrants' countries of origin and destination." Journal of Political Economy 85(5), $1001-1020$.

Van der Berg, Servaas, Rulof P. Burger, Murray Leibbrandt, and Cecil Mlatsheni. 2002. "Migration and the changing rural-urban interface in South Africa: What can we learn from census and survey data?" Paper presented at the CSAE Conference, Oxford, U.K.

Wildasin, David E. 1991. "Income redistribution in a common labor market." American Economic Review 81(4), 757-774.

Young, Alwyn. 2013. "Inequality, the urban-rural gap and migration." Quarterly Journal of Economics 128(4), 1727-1785. 